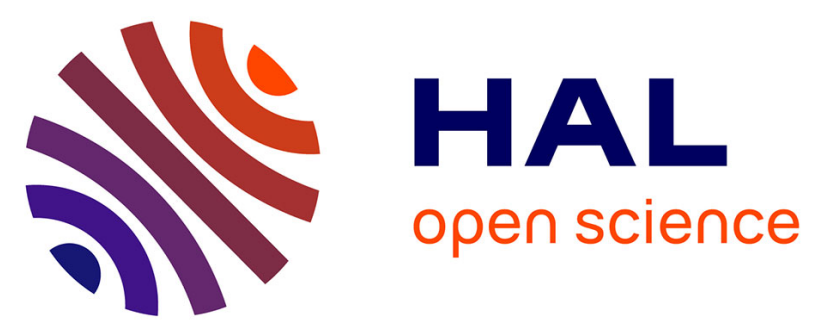

\title{
Simple envelope-based reconstruction methods can infer light partitioning among individual plants in sparse and dense herbaceous canopies
}

Gaëtan Louarn, David da Silva, Christophe Godin, Didier Combes

\section{- To cite this version:}

Gaëtan Louarn, David da Silva, Christophe Godin, Didier Combes. Simple envelope-based reconstruction methods can infer light partitioning among individual plants in sparse and dense herbaceous canopies. Agricultural and Forest Meteorology, 2012, 166-167, pp.98-112. 10.1016/j.agrformet.2012.06.014 . hal-00828848

\section{HAL Id: hal-00828848 \\ https://hal.inria.fr/hal-00828848}

Submitted on 7 Jan 2015

HAL is a multi-disciplinary open access archive for the deposit and dissemination of scientific research documents, whether they are published or not. The documents may come from teaching and research institutions in France or abroad, or from public or private research centers.
L'archive ouverte pluridisciplinaire HAL, est destinée au dépôt et à la diffusion de documents scientifiques de niveau recherche, publiés ou non, émanant des établissements d'enseignement et de recherche français ou étrangers, des laboratoires publics ou privés. 
Simple envelope-based reconstruction methods can infer light partitioning among individual plants in sparse and dense herbaceous canopies

5 Louarn Gaëtan ${ }^{1 *}$, Da Silva David ${ }^{2}$, Godin Christophe $^{3}$, Combes Didier $^{1}$

${ }^{1}$ INRA UR4 URP3F, BP6, F86600 Lusignan, France

${ }^{2}$ Plant Sciences Department, UC Davis, One Shields Avenue, Davis, CA 95616, USA

${ }^{3}$ INRIA UMR DAP, TA96/02 CIRAD, Avenue Agropolis, F34398 Montpellier, France *corresponding author: \{gaetan.louarn\}@ lusignan.inra.fr

Tel: $33(0) 549556063$

Fax : $33(0) 549556068$

Running title: Reconstruction methods to estimate light partitioning among individual plants 


\section{Abstract}

Light interception controls the growth potential of species and individuals in plant communities. However, the effects of competition for light on short term vegetation dynamics are still poorly understood. This is in part due to a lack of quantitative methods to estimate this resource capture by individual plants within a canopy. In this paper, we studied the light interception of herbaceous plants with contrasting architectures (monocultures and binary mixtures) grown at high or low density and sought to determine the important architectural features necessary to account for light partitioning among individual plants. It was shown that the plant populations studied were typical of a wide range of competition intensities, ranging from sparse plants to dense size-structured populations. Plant representations using whole plant envelopes with homogeneous leaf area density (LAD) were not reliable to estimate light partitioning, irrespective of the accuracy of envelope definition. Accounting for heterogeneous LAD within plants helped to solve this problem in both sparse and dense canopies. The relative importance of traits however changed with competition intensity and was different from reports made on isolated plants. Simple envelope-based reconstructions were finally shown robust enough to support parameterisation from a tractable set of traits measured in the field provided that height and vertical LAD gradient were characterised.

Key-words: Competition, light partitioning, architectural traits, virtual plants, 3D models, grass-legume mixtures 


\section{Introduction}

Competition for resources is one of the major processes controlling plant growth and explaining the structure and dynamics of plant communities (e.g. Harper, 1977; Grime, 1979; Tilman, 1988). In particular, competition for light is of primary importance because it determines the energy available for all physiological processes and partially drives the acquisition of other resources (Keddy, 2001). Furthermore, as light availability declines exponentially with distance from the top of the canopy, minor differences in plant size can have major effects on the quantity and quality of the light available to surrogate plants. Light is thus typically a resource that is pre-empted by taller plants. This asymmetric competition is

60 considered to be the primary cause of both size inequality in even-aged populations (Weiner and Thomas, 1986; Schwinning and Weiner, 1998) and species succession in productive habitats (e.g. Werger et al., 2002 ; Hautier et al., 2009).

Although plant species vary considerably in their architecture, models predicting light interception have focused on a limited number of quantitative features such as total leaf area,

65 leaf angle distribution and leaf dispersion (Ross, 1981; Campbell and Norman, 2000). In monospecific plant stands, a ‘turbid medium' analogy (i.e. canopy structure seen as a horizontally homogeneous layer of random small particles) is generally assumed to model light extinction according to the Beer-Lambert's law (Monsi and Saeki, 1953), to which a supplemental leaf dispersion parameter can be introduced to empirically deal with the nonrandom clumping of foliage (Nilson, 1971; Cescatti and Zorer, 2003). Modelling the competition for light in multispecific canopies basically follows the same principles within a homogeneous vegetation layer (Rimmington, 1984; Sinoquet and Bonhomme, 1992). This made it possible to calculate light partitioning among species from the Beer-Lambert's law using a series of horizontally homogeneous layers to account for the between-species differences in maximal height and average vertical distribution of leaf properties (Sinoquet et 
al., 2000). Such an approach has been widely used in intercropping models (Malézieux et al., 2009 for a review) and has proved accurate for a wide range of canopy structures to quantify light partitioning between species (Barillot et al., 2011).

In spite of these quantitative methods, our ability to predict short-time changes (ranging from a growing season to a few years) in productivity and species composition as a result of interspecific competition is still limited, even in simple cultivated plant communities (Malézieux et al., 2009; Louarn et al., 2010). This may arise in part because the fate of elementary units controlling population dynamics in each species (i.e. individual plants in most cases, Harper, 1977) is not considered in these approaches. Indeed plant size distributions in populations under severe light competition do not usually follow a Gaussian distribution, but rather a lognormal or multimodal distribution (Obeid et al., 1967; Weiner and Thomas, 1986; Gosse et al., 1988). The representation of a species through an average plant (as done in the multilayers models) may thus no longer be suitable to infer the population behaviour (Lomnicki, 1988; Berger et al., 2008). On the other hand, many theoretical models of plant population

90 dynamics relying on quantitative resource partitioning among individuals were developed to explain self-thinning, changes in population's size structure as well as shifts in genotypic or species composition (Hara, 1988; Tilman, 1988; Damgaard, 2004). So far, these approaches are however mainly phenomenological and consider resource partitioning qualitatively, using simplified partitioning processes (e.g. use of the zone of influence concept which does not discriminate between resource types but can be applied with various degrees of asymmetry in favour of larger plants; Hara and Wyszomirski, 1994) and/or simplified plant representations (Tilman, 1988; Chave, 1999). Improving our ability to study and model resource capture at the plant scale, and light interception in particular, would constitute a breakthrough that could enable significant improvements in the quantitative predictions of plant population models. 
In comparison with whole canopy light interception and light partitioning between species, quantification of light interception and partitioning by individual plants into a canopy has received little attention (Ross, 1981; Pearcy and Yang, 1996). In theory, light interception and partitioning among any components of a canopy can easily and accurately be computed using light transfer models, provided that the explicit geometry, i.e. three dimensional (3D), is

105 known and labelled at the organisational level of interest (Chelle, 2005; Da Silva et al., 2008). In practice, however, it remains difficult to measure (Sonohat et al., 2002) and full geometric information is often out of reach because a tedious and sometimes intractable amount of work is necessary to collect the corresponding data (e.g. trees in a forest canopy). Full geometric information is also likely to be unnecessary since more simple representation of plant 3D

110 structure can be achieved (basically, a crown envelope, an average crown density and a leaf dispersion parameter) that enable proper quantification of light interception by isolated plants (Duursma et al., 2011). Several strategies based on simplified plant measurements have therefore been proposed to enable the computation of light partitioning at the plant level, mainly for orchard and forest management purposes. They are based on the coupling of light

115 models with simplified envelope-based plant structures (e.g. envelope-based turbid medium, Norman and Welles, 1983; Johnson and Lakso, 1991; Law et al., 2001) or stochastic 3Dexplicit statistical reconstructions (Giuliani et al., 2005; Sonohat et al., 2006; Louarn et al., 2008a). The rationale behind the possible simplifications regarding actual plants within a canopy remains however poorly understood. The traits leading to maximal light interception 120 at one organisation level may indeed not necessarily lead to success at another. For instance, vertical leaf area gradients are negligible to explain light interception by a single species but are crucial to explain light partitioning in a plant community. Similarly the traits important to consider in the plant structure representation may change between isolated plants and plants within a community. They could also differ according to the intensity of the light competition 
125 induced by neighbouring plants (Ross, 1981; Hara and Wyszomirski, 1994; Hikosaka et al., 2001). A simulation study by Wang and Jarvis (1990) allowed to rank the importance of total plant leaf area, crown shape, leaf clumping and leaf angle distribution in the light partitioning of even-size monospecific tree stands. Yet, a lack of understanding of how these main determinants of light interception may vary with plant architecture and the intensity of the

130 competition for light still hampers the development of reliable simplified plant structures that could be applied in broad ecological and agronomical contexts. Furthermore, because these approaches were mainly dedicated to trees, a direct assessment of simplified envelope-based plant representations against actual 3D structures has never been challenged so far within a community.

135 By studying herbaceous plants with contrasted architectures grown at high or low levels of competition for light, the objectives of the present study were: i) to determine the relative importance of plant crown shape, total plant leaf area, leaf area clumping and leaf angle distribution in accounting for light partitioning among individual plants in herbaceous communities with contrasted competition intensities and ii) to assess the performance of

140 simple reconstruction methods relying on these traits to infer light partitioning from simple field measurements. Monocultures and binary mixtures of grass and legume were chosen as a model for this case study because they represent a broad range of the architectural types frequently encountered in natural and cultivated plant communities, and because the exhaustive 3D description (i.e. 3D geometry and topology, Godin et al., 1999) of these plants

145 remains accessible, even at a community level. A comparison of envelope-based models enabled to test for the relative importance of traits controlling plant size and leaf properties. The assessment of a simple model derived from the previous analysis was performed using only simple field measurements for the parameterisation. 


\section{Materials and Methods}

\subsection{Plant materials and growing conditions}

Two experiments were carried out outdoors at the INRA Lusignan station $\left(46.43^{\circ} \mathrm{N}, 0.12^{\circ} \mathrm{W}\right)$ between April 15 and September 15 in 2009 and 2010. During the first year, pure stands of alfalfa (Medicago staiva L. cv Orca) were studied at two planting densities, corresponding

155 respectively to a dense plant population (hereinafter referred to as HD for high density; 460 plants. $\mathrm{m}^{-2}$, about $1 \mathrm{~m}^{2}$ stand), and to an open field with a low density population of plants (hereinafter referred to as LD; 50 plants. $\mathrm{m}^{-2}$, about $2 \mathrm{~m}^{2}$ stand). In the second year, the stands studied consisted in 50/50 alfalfa (Medicago sativa L. cv Orca) - tall fescue (Festuca arundinacea Schreb. cv Noria) mixtures at the same two densities (i.e. 25 plants. $\mathrm{m}^{-2}$ each at

160 LD and 230 plants. $\mathrm{m}^{-2}$ each at HD). Each plant was grown in an individual pot $(5 \mathrm{~cm}$ diameter $\mathrm{x} 40 \mathrm{~cm}$ high at $\mathrm{HD} ; 10 \mathrm{~cm}$ diameter $\mathrm{x} 25 \mathrm{~cm}$ high at $\mathrm{LD}$ ) to ensure that they were competing for light only. In all situations, the pots were arranged according to a hexagon lattice for planting, so that all plants were equidistant within the stand (Harper, 1961; Boffey and Veevers, 1977). In addition, each individual in the mixture was surrounded by three of its

165 own species and three of the other species. The pots were filled with a medium made up of sterile potting mix, sand and brown soil $(1: 1: 1 \mathrm{v} / \mathrm{v})$. They were ferti-irrigated three times a day with a complete nutrient solution.

\subsection{Size structure characterisation of the studied populations}

170 For each stand, plants were cut to $5 \mathrm{~cm}$ above soil level every $4-5$ weeks during the growing season, at the early bloom stage of alfalfa. This occurred in particular just following the two periods of architectural characterisations described in the next section. At each harvest 100 plants at $\mathrm{HD}$ and 60 plants at LD were individually collected, dried $\left(48 \mathrm{~h}\right.$ at $\left.60^{\circ} \mathrm{C}\right)$ and weighted. Asymmetry in population's mass distribution and inequality of resource 
175 partitioning among individuals of each species were assessed using the Gini coefficient $(G)$, which is a measure of the relative mean difference (i.e. the arithmetic average of the differences between all pairs of individuals; Sen, 1973; Weiner and Solbrig, 1984):

$$
\mathrm{G}=\sum_{i=1}^{n} \sum_{j=1}^{n}\left|x_{i}-x_{j}\right| /\left(2 n^{2} \bar{x}\right) \quad \text { Eq. } 1
$$

Calculated $G$ values were multiplied by $n /(n-1)$ to give unbiased values $\left(G^{\prime}\right)$. G' values range

180 between 0 (all the individuals share resources equally) and 1 (all the resources captured by a single individual). As light was the only contested resource in the experiments, G' was used as an indicator of competition intensity in the different studied populations.

\subsection{Three-dimensional digitising and plant reconstructions}

185 For each stand, 3D digitisations were performed at two stages of development: once during vegetative development in the course of the first growth after sowing (about 650 degree days after emergence) and once at the end of a summer regrowth period at the early bloom stage of alfalfa. A group of neighbouring plants located in the centre of each stand were individually and carefully extracted from the canopy. This represented 20 plants at LD (on a soil surface of

190 about $1400 \mathrm{~cm}^{2}$ ) and 40 plants at HD (on a soil surface of about $900 \mathrm{~cm}^{2}$ ). They were then measured indoors using an electromagnetic 3D digitizer (3Space Fastrak, Polhemus Inc., Colchester, VT, USA) and 3A software (Adam et al., 1999). This enabled us to record the multi-scale topology of each plant and describe it as a multi-scale tree graph (MTG) (Godin et al., 1999). At each scale (i.e. branches, shoots, leaves), the plant was regarded as a set of

195 botanical components of the directly finer scale, arranged as a rooted tree graph. Additionally the spatial coordinates of all organs and other attributes related to plant/organ geometry were measured. Details on the digitisation method are available in the article by Sinoquet and Rivet (1997). Only those features specific to the two species studied here are presented below. 
In the case of alfalfa, leaves were mainly described through the position, length and orientation of the central leaflet. Lateral leaflets size and central leaflet width were only measured on a sub-sample of phytomers from each plant. Allometric relationships were built specifically for each plant using these data, considering i) central leaflet length as a predictor of lateral leaflet length, and ii) leaflet length and phytomer position along the stem as predictors of leaflet width. Direct measurements of the right and left-hand side leaflets were therefore only required in the case of clear asymmetry regarding their size or orientation according to the usually regular trifoliate pattern. Otherwise, they were added during the reconstruction process, their size and geometry being deduced from the central leaflet by rotation and the application of a plant-specific scaling factor. Figure A (supplementary material) confirm the accuracy of such size estimates as compared to hand-measured lengths.

210 For tall fescue, 3D leaf records involved the description of a midrib path through a set of at least three points and the systematic measurement of maximum leaf width. For uncut grass leaves, we accounted for changes in leaf width along the leaf using the parabolic relationship proposed by Prévot et al. (1991). This was parameterized using multiple leaf width measurements on a sub-sample of leaves. For cut leaves, we assumed that leaf width remained 215 constant and equal to the maximum leaf width over the whole leaf length. The reconstruction process was achieved using the PlantGL toolkit (Pradal et al., 2009) in the Openalea platform (Pradal et al., 2008; http://openalea.gforge.inria.fr). Only leaves were considered as parts of the virtual plants in the present study. Alfalfa leaflets were represented using a unique, flat 3D mesh with the same allometric properties as actual leaflets. This mesh was then scaled, rotated and translated wherever required in order to fit the digitised data. Tall fescue leaves were represented through a succession of trapezes for each leaf segment. As the orientations of leaf surfaces were not directly measured, they were inferred for each leaf 
segment from the cross product of the vectors defined by two consecutive segments. The tip of the leaf conserved the same orientation as the preceding leaf segment.

225 Once separately characterised, multi-scale plant descriptions were then gathered according to their actual position and orientation in the stand in order to build up virtual canopies. Four of these corresponded to actual canopies at each density (i.e. pure alfalfa legume stands, grasslegume mixtures stands at two stages of development). In addition, two supplementary virtual stands for pure grass were built to serve as controls and facilitate the analysis of light partitioning in the mixtures. To achieve this, alfalfa plants in the mixtures were replaced by tall fescue plants on the basis of the closest dry matter yield at harvest for each stage and density. Overall, six canopies were thus generated at each density (Figure 1).

\subsection{Comparison of envelope-based models: role played by the main attributes defining plant} envelopes and by within envelope leaf properties

Using the dataset of digitised canopies, it was possible to compare a range of simplified plant structures generated from envelope-based models from the literature (Table 1). These particular models were chosen because the series of whole plant boundary envelopes they represented (namely plant convex boundary envelope or hull,p, ellipsoid, vertical cylinder and vertical tessellation prism) corresponded to a regular gradient of simplification associated with traits simple to understand (namely height, maximal diameter and crown asymmetry, Fig. 2). A null model was also designed so as it represented all plants with the same envelope irrespective of their actual 3D structure. It thus considered none of the previous traits and produced non-overlapping hexagonal prisms (because all the plants were equidistant) of the same height and basal area.

For each model, geometric envelopes were fit to each individual 3D digitised plant structure of the 12 studied canopies using the PlantGL toolkit in the Openalea platform (Pradal et al., 
2009). In the null model, height was adjusted to the maximal canopy height. A turbid medium of discrete, small 3D leaf elements for the boundary envelope was then generated within each envelope (Louarn et al., 2008a, b). The size of leaf elements (i.e. triangles of $0.5 \mathrm{~cm}^{2}$ ) had previously been optimised to limit the computation time during light interception calculation without affecting light partitioning among plant shoots/tillers (i.e. at a finer scale than plant scale).

In order to discriminate between effects related to the relative size of envelopes and to withinenvelope leaf properties, six successive runs of simulations were carried out for each of the geometrical models tested using different assumptions with respect to the total plant leaf area, leaf area clumping and leaf angles within envelopes (Table 2). The first two sets of simulations assumed leaf elements were distributed at random using uniform distributions along $\mathrm{x}, \mathrm{y}$ and $\mathrm{z}$ axes (homogeneous LAD within envelopes) but differed in plant leaf areas: one used the average plant leaf area for the whole stand (total leaf area of the species divided by the number of plants) and the other used the actual plant leaf area obtained from the corresponding digitised plants. These first two runs aimed at assessing the role of the various traits involved in plant boundary envelope definition and weight it as compared to average plant LAD.

265 The next two simulation runs explored the importance of heterogeneous LAD distribution within plant boundary envelopes to explain light partitioning. Empirical functions were defined from 3D digitised plants to account for relative plant leaf area distribution along $\mathrm{x}, \mathrm{y}$ and $\mathrm{z}$ axes. Basically it consisted for each plant in two 10-classes histograms of relative leaf area density along either the z-axis (vertical distribution) or in the plane of the maximal plant diameter (horizontal distribution). These density functions were used to generate non-random distribution of leaf area within plant envelopes, the first considering the vertical clumping of leaf area only $(z)$ and the second considering both vertical and horizontal clumping $(x y z)$. In 
addition, a supplemental reference situation was designed for each plant which consisted in describing actual leaf aggregation at a finer organisation scale than plant scale (i.e. shoots in alfalfa and tillers in tall fescue). Such an approach was previously shown to yield plant representations with suitable leaf dispersions to infer light interception by isolated plants (Sonohat et al., 2006; Da Silva et al., 2008). To do so, the convex boundary envelope geometry was fit to each individual shoots of the plant (instead of the plant as a whole) in order to account for heterogeneous leaf area between shoots, dispersion of shoots within the plant envelope and voids in terms of LAD (Hull, s, Table 1).

Finally, the two last runs assessed the sensitivity of light partitioning to leaf elevation distribution $(g(\alpha))$. Plant to plant leaf angle distributions (defined from the elevation angles of 3D surfaces in the plant digitisations) were replaced by generic distributions from the literature for each plant species (i.e. erectophile and plagiophile distributions for grass and legumes respectively; Sinoquet and Andrieu, 1993):

$$
\begin{array}{ll}
g_{\text {erect }}(\alpha)=2 / \pi \cdot(1-\cos (2 \alpha)) & \text { Eqn. } 2 \\
g_{\text {plagio }}(\alpha)=2 / \pi \cdot(1-\cos (4 \alpha)) & \text { Eqn. } 3
\end{array}
$$

In a first step, simulations were performed with the leaf angles distributions that best fit actual leaf properties for each species. In a second step, distributions were switched (i.e. plagiophile and erect distributions for grass and legume, respectively) so as leaf angles were unpaired.

\subsection{Assessement of a simple envelope-based reconstruction method parameterised using field}

\section{measurements}

The previous sensitivity analysis was designed to assess the potential of envelope-based reconstruction models to build up faithful plant representation with respect to light interception properties within a canopy. It however can not inform us about their practical usefulness, since parameterisations of boundary envelopes, leaf area surfaces and clumping 
functions were directly extracted from 3D plant digitisations. A last set of simulations was thus performed using a tractable series of field measurements to parameterise a simple envelope-based reconstruction method. It involved:

i) hand-measurements of maximum height and maximum diameter for each plant to define the boundary envelope as a vertical cylinder

ii) estimates of relative vertical leaf area distributions for each species in all the studied stands

305 To do so, leaf area was measured for every $10-\mathrm{cm}$ layer on a sub-sample of plants at harvest using a Licor 3100C planimeter (LiCor Inc., Lincoln, Nebraska). The vertical distribution was averaged at the canopy level for each species and canopy to define a unique relative vertical clumping function for all plants in a given situation. The horizontal clumping function was defined as a Gaussian distribution with $\sigma=1 / 6$ of maximum envelope diameter. This enabled to account for the horizontal leaf aggregation in the center of the plant observed in many herbaceous plants including grasses and alfalfa (Ross, 1981). Equations 2 and 3 were used to define leaf angle distributions in grass and legume respectively.

\subsection{Computation of light interception by individual plants}

315 Light interception was computed on the leaf surfaces of the 3D plant structures (either digitised or derived from envelope based reconstructions) using the radiative transfer model CANESTRA (Chelle and Andrieu, 1998) available in the Openalea platform (Pradal et al., 2008). Radiative budgets of individual leaf elements and of the soil compartment were calculated, so that it was then possible to precisely sum up the amount of light intercepted by leaf elements at various scales, including plant and whole canopy scales. For envelope based reconstructions in mixtures, the simulations were rendered for each species separately by 
representing the target species by its simplified 3D representations and the other species with its digitised structures.

Incoming light sources were distributed to simulate an overcast sky with a total irradiance equalling 1 on a horizontal plane. These conditions were approximated using 40 light sources positioned in the centres of four elevations x 10 azimuth sectors, the relative light intensities being computed according to the standard overcast model (SOC, Moon and Spencer, 1942). For the different plant representations, we compared the amount of light intercepted by each individual plant expressed in arbitrary units.plant ${ }^{-1}$ (since the incoming PAR intensity was normalised). Canopy light interception efficiency (LIE) was calculated for each species as the proportion of incoming light (\%) captured by all plants of this species.

\subsection{Statistical analyses}

Simulated and measured (i.e. computed from digitisations) amounts of intercepted PAR by individual plants were compared for each stand using the root mean square error (RMSE) calculated as follows:

$$
\text { RMSE }=\sqrt{\frac{\sum_{i=1}^{n}\left(s_{i}-m_{i}\right)^{2}}{n}} \quad \text { Eqn. } 4
$$

where $s_{i}$ and $m_{i}$ are the $\mathrm{i}^{\text {th }}$ simulated and measured values respectively, and $n$ is the number of observations.

340 Because the amount of light captured varied considerably between individual plants in the two species and between density treatments, we used a normalised measure of the model error, the coefficient of variation of the RMSE $\left(\mathrm{CV}_{\text {rmse }}\right)$, to compare the different situations studied. $\mathrm{CV}_{\text {rmse }}$ is defined as the ratio between the RMSE and the mean of observed values. The linear correlation between simulated and measured values was assessed using the Pearson coefficient $r$ and the $\operatorname{lm}$ (linear model) procedure under R software (http://www.r- 
project.org/). Potential bias and discrepancy according to the expected 1:1 line were quantified using slope $a$ of the $s=a . m$ model after testing for non-significant intercept. In addition, a measure of the balance between the relative goodness of fit of a model and its complexity (i.e. its number of parameters) was estimated through the Akaike's Information

Criterion (AIC; Burnham and Anderson, 2002) using the AIC procedure under R software:

$$
\mathrm{AIC}=-2 \cdot \log -\operatorname{lik}_{\mathrm{M}}(\mathrm{X}, \theta)+k \cdot \mathrm{n}_{\mathrm{par}} \quad \text { Eqn. } 5
$$

Where $\log -\operatorname{lik}_{M}(X, \theta)$ is the maximized loglikelihood for the model and data, $n_{\text {par }}$ is the number of parameters (total number of parameters used to define plant envelope geometry, clumping functions and leaf angle distributions) and $k$ the penalty per parameter to be used $(k=2)$. AIC values thus provide a means for model selection in a series of models of increasing complexity by considering a penalty for the number of parameters used. Given a set of candidate models for the data, the preferred model is the one with the minimum AIC value. For the models we assessed using a convex Hull envelope (which can not be described by a parametric equation contrary to the other envelopes tested), the number of parameters to define the geometry was assumed equal to the average number of extreme points delimiting the convex envelope (20).

One-sample Kolmogorov-Smirnov tests (ks.test procedure under R sofware) against a theoretical Gaussian distribution with the same average value and standard deviation were used to assess the normality of mass distributions in each plant populations. Two-sample

365 Kolmogorov-Smirnov tests were used to compare the distributions of plant leaf area by PAR irradiance classes for simulated and digitized 3D structures. The null hypothesis of identical distributions was rejected for $\mathrm{p}$-values $<0.05$.

\section{Results}


Dry mass distributions of plants in the studied populations are presented in Figure 3. At low density (LD), irrespective of species and dates of measurements, all plant populations presented a size distribution that did not significantly differed from a normal distribution (pvalues $>0.05$ for all $\mathrm{KS}$ tests). G' coefficients, accounting for the degree of size inequality in

375 the populations, remained low, between 0.17 and 0.26 . By contrast, at high density (HD), plant size distributions were normal during the first growth cycle after sowing (stage 1), but significantly differed from normal at the end of the second regrowth period (stage 2) for both the pure legume stand and grass plants in mixture $(\mathrm{KS}$-tests p-values $<0.001)$. Moreover a marked positive skewness appeared for all HD populations at this stage. Gini coefficients

380 significantly increased $\left(\mathrm{G}^{\prime}\right.$ in the range $\left.0.34-0.52\right)$ as compared to LD and HD-stage 1, indicating than a higher proportion of total plant biomass was contained in a smaller number of dominant individuals. The legume component in mixture however displayed an asymmetry that was clearly less important than in a pure stand.

\subsection{Canopy light interception efficiencies}

Light interception efficiencies and light partitioning among species in mixtures were calculated from the digitised plants gathered in virtual stands and are presented in Figure 4. At $\mathrm{HD}$, the proportion of incoming light reaching the soil surface was very low (below $6 \%$ in all situations) indicating a high canopy light interception efficiency. At LD, this proportion was significantly higher, in the $25-55 \%$ range, indicating much more open canopies. The only exception was the pure legume stand at stage 2 where light interception efficiency was similar to those observed at HD. In mixtures, overall light partitioning between the grass and legume components was relatively even at LD but was strongly in favour of the legume component at HD (proportion of light intercepted $>80 \%$ ). 


\subsection{Influence of total plant leaf area and relative plant size on light distribution among individual plants}

The light interception properties of models producing gradually simplified plants structures were compared to those of digitised plants in order to quantify the relative contribution of various morphological traits to light partitioning. Figure 5 shows an example of the relationships established for each model and each virtual stand studied as well as the statistics derived. RMSE, the slope $a$ of the linear relationship and $\mathrm{r}^{2}$ were respectively used to assess model error, model bias and the proportion of interplant variations explained by the model. These statistics are summarised in Table 3 for all the simulations comparing model boundary envelopes with the assumption that plants all have equal total leaf area (i.e. only traits such as height, maximal diameter and asymmetry in the shape of the envelope contributed to explain light partitioning). Under this assumption the null model thus considers all plants having the same envelope and the same leaf area density. Therefore they theoretically all share the light equally in a pure stand with equidistant individuals. As one might expect, non-significant

410 relationships with the light partitioning measured $\left(r^{2}<0.18\right)$ were thus found in all studied pure stands, confirming that relative plant size and/or plant leaf area were required to explain interplant variability in light interception. In mixtures, the null model additionally informed us about any variability in local microclimate induced by the neighbour species (since the simulations were rendered for each species separately by representing the other species with

415 its digitised structures). Non-significant relationships were found in 3 out of 4 canopies, but in one case (grass in mixture, LD-1), the still-holding correlation $\left(\mathrm{r}^{2}=0.49\right)$ indicated a heterogeneous light microclimate in the vicinity of grass plants. The identity of neighbour plants alone did contribute to explain a significant part of inter-plant variations in light interception in this situation. 
Adding simply height as a parameter to differentiate individual plants (Tessel model, Table 3) resulted in no improvement except in pure legume stands, both at LD and HD. In these four stands, a significant part of inter-plant variance was explained $\left(\mathrm{r}^{2}\right.$ close to 0.5 at HD) but little or no progress was made about model errors. Plant representations further considering plant maximal diameter (Cylinder) or envelope asymmetry in the horizontal plane (Ellipsoid) did 425 not generally improve the relationships between measured and simulated light interception. Even by considering the exact plant convex boundary envelopes (Hull model), relationships were non significant in 4 out of 8 stands at LD (considering also grass in mixture, LD-1 since no change was observed as compared to the null model) and two out of 8 stands at HD. These were preferentially grass stands whereas legume stands had generally a higher part of their 430 inter-plant variability in light capture explained by differences in envelope size (up to 69 to $73 \%$ at HD stage 2). However, irrespective of the plant stand, model errors with the most detailed envelope representation remained very high: $\mathrm{CV}_{\text {rmse }}$ changed between stands depending on the inter-plant dispersion of light capture (not shown), but values always remained close to the estimates made from the null model, indicating that no progress was 435 made from a quantitative perspective.

Table 4 presents a second comparison of model boundary envelopes but considering all plants with their actual total leaf area. The null model in this series thus represents the case where plants only differentiate each other by their total leaf area. As a counterpart of the Hull,p model in Table 3 (plants only differentiate each other by their relative size), it is striking that

440 differences in leaf area explained a considerable part of inter-plant variations in light interception. At LD, 69 to 99\% of variance was explained by leaf area alone. An important decrease of $\mathrm{CV}_{\text {rmse }}$ was also observed, together with limited biases (biases, calculated as $|a-1|$, remained below $6 \%$ except for grasses in mixture and pure legume stage 2 ). At HD, the contribution of leaf area alone was smaller but it still explained more inter-plant variance (22 
to $55 \%$, one non-significant relationship) than size variability did in most cases (except for pure legume). Providing simple dimension traits such as height (Tessel model) and diameter (Cylinder, Ellipsoid models) in addition to total leaf area resulted in quite opposite effects in the two species. In legumes, introducing height and diameter greatly improved model performance in pure stand at HD (76 to $96 \%$ of variance explained, marked decreased in model error and biases) and had little or no effect at LD and in mixtures at HD. In grasses, little or no improvement was shown. On the contrary, considering these traits resulted in higher model errors and poorer variance explained than with the null model. These negative effects were more important at HD than at LD.

The most detailed plant representations (Hull,p model, Table 4), which combined actual plant 455 leaf area with exact plant convex boundary envelopes, performed clearly better than all other models. All the relationships between observed and simulated light interception were significant and explained more than $70 \%$ of inter-plant variance (except for HD grass in mixture, stage 2). In grasses in particular, a dramatic increase of model performance was recorded as compared to more simple ellipsoids or cylinders, indicating a significant role of

460 relative plant size that was not accounted for by the range of simple envelopes tested so far (i.e. asymmetry along vertical axis). In legumes, hull representations also clearly helped to improve predictions in light partitioning, although less than in grasses (except for HD legumes in mixture). Overall however, these detailed representations, which assumed a homogeneous leaf area density within plant envelopes, did not prove to be reliable

465 quantitative tools to infer light partitioning at the plant scale. Indeed, significant biases were observed in mixtures (up to $38 \%$ for grasses in mixture) and model errors remained high in dense canopies $\left(\mathrm{CV}_{\text {rmse }} \geq 20 \%\right.$ in 6 out of 8 situations).

\subsection{Influence of clumping and heterogeneous leaf area distribution within envelopes}


470 To further analyse the impact of plant structure on light partitioning, we assessed the role of heterogeneous leaf area distribution within plant boundary envelopes. Three cases were distinguished: one considering finer envelope description than the plant scale (i.e. hull envelopes fitted at the shoot scale to account for heterogeneous leaf area between shoots and heterogeneous dispersion of shoots within the plant envelope), one considering plant envelopes varying in their vertical leaf area gradients ( $z$ simulations) and the other considering vertical and horizontal leaf area gradients together ( $x y z$ simulations). Table 5 presents the summary statistics for hull and cylinder envelopes (see supplementary material, Table A for the whole set of models tested). Adding information on leaf clumping had a profound influence on estimates of light interception. Using shoot boundary envelopes 480 (Hull,s) generally led to unbiased simulations and better model prediction as compared to plant envelopes with homogeneous LAD (Hull,p). More than $80 \%$ and $95 \%$ of inter-plant variance could be explained, respectively, at HD and LD. A two-fold decrease in model error was observed in average, both at $\mathrm{HD}\left(\mathrm{CV}_{\text {rmse }}\right.$ reduced from $19 \%$ to $\left.10.6 \%\right)$ and $\mathrm{LD}\left(\mathrm{CV}_{\text {rmse }}\right.$ reduced from $10.3 \%$ to $5.8 \%$ ). Predictions considering heterogeneous leaf area distributions 485 were more particularly improved for grasses and for plants in mixtures, indicating than for these stands differences in relative LAD distribution rather than in relative plant size explained inter-plant variance in light interception. At LD, as results were already quite accurate irrespective of the boundary envelopes (Table 3), clumping mostly helped to consolidate that part of variance which was explained and to reduce bias.

490 The use of more simple plant envelopes combined with empirical function of leaf area distribution (Hull,p, $z$ and $x y z$ simulations) enabled to show that both vertical and horizontal clumping had generally positive effects on estimates of light partitioning. Whereas the introduction of vertical gradients was more effective in improving predictions in light partitioning at HD ( $z$ simulations were as good as $x y z$ simulations in 6 out of 8 canopies), both 
vertical and horizontal gradients were shown to play equivalent roles at LD ( $z$ and $x y z$ simulations presented a regular progression from homogeneous Hull,p toward Hull,s). Exceptions were observed for pure legume stands at LD, where homogeneous representations already performed quite well (thus no improvement was observed with heterogeneous representations), and for HD grasses in mixtures where horizontal heterogeneity played a significant role.

Interestingly, the use of plant envelopes more simple (Cylinder) than the exact plant convex boundary envelopes (Hull,p) did not resulted in a lower ability to predict light partitioning. The overall impact of clumping compared to relative plant size differed between the two species (supplementary material, Tab. A). In grasses, the improvement, in terms of model error, achieved by introducing clumping largely exceeded the differences between simplified boundary envelope types. In legumes on the other hand, the influences of clumping and relative plant size appeared to be of the same order of magnitude. In both species, the best representations using simplified envelopes were usually achieved using cylinders with $z$ or $x y z$ clumping (Table 5). Irrespective of species and density, this simplified representation

510 performed better (13 out of the 16 canopies) than hull,p envelopes with homogeneous LAD. In almost all cases, it also performed as well as hull,p envelopes with the same clumping properties ( $z$ or $x y z$ clumping). In fact, the results were as accurate as reconstructions at the shoot scale (Hull,s) in 12 out of 16 cases, resulting in unbiased quantitative estimates of light partitioning in all but one canopy $\left(\mathrm{CV}_{\mathrm{rmse}}>15 \%\right.$ and bias $>5 \%$ only for $\mathrm{HD}$ grass in mixture, 515 stage 1).

The use of simple envelopes with $z$ or $x y z$ clumping was finally also supported by criterions dedicated to the comparison of models of increasing complexity (Figure 6). AIC enables to identify trade-offs between accuracy and complexity of the models. Typical "U" shape curves were observed for a majority of situations (HD and LD mixtures) when comparing models of 
increasing complexity in their boundary envelope definition on the basis of AIC (e.g. Fig. $6 b, c)$. This confirmed that the more parsimonious reconstructions to infer light partitioning among individuals were based on envelopes of intermediate complexity. Refining envelope delimitation beyond the consideration of maximal height and diameter was almost never rewarded. On the other hand, over-simplifications were frequently shown for Tessel and Null models (significant loss of information visible from the increased AIC value in spite of a lower number of parameters). The only exception concerned LD pure stands at stage 1 (e.g. Fig. 6a) where, as presented in the previous section (Tab. 4), variations in plant leaf area accounted for most of the inter-plant variation in light interception. In this case, the null model using actual plant leaf area was the most parsimonious. In all other cases it was also

530 shown that AIC decreased when including the parameters describing empirical clumping functions (simulation runs 3 and 4 as compared to run 2). It was thus worth adding these parameters, particularly for plants at HD and for subordinate plants in mixtures (e.g. Fig. 6d).

\subsection{Influence of leaf angle distributions}

535 The sensitivity of envelope-based reconstructions to the distribution of leaf angles was also examined taking the two most accurate representations obtained above at the plant scale as study cases (i.e. hull,p and cylinder envelopes with xyz clumping, Table 6). In a first step, distributions from the literature were substituted for each species to the distributions of elevation angles measured from digitisation. Such a simplification had a remarkably small

540 impact on light partitioning among individual plants, irrespective of species and density. Model errors and the part of inter-plant variance explained never changed by more than $\pm 2 \%$ when compared to the corresponding simulations with measured distributions (Table 5). In a second step, simulations were performed switching the distributions between species. The two species behaved quite differently under this assumption. Light interception by grass plants 
545 tended to be enhanced whereas it tended to decrease for legumes. These changes had a quite small impact for pure stands at HD but increased dramatically model errors at LD (except for LD pure legume, stage 2) and at HD in mixtures. This led to a general degradation of the model predictions under these conditions and a marked overestimation of light interception for grasses (up to $40 \%$ to $60 \%$ bias in mixtures) and a slightly less marked underestimation

550 for legumes (up to $-7 \%$ to $11 \%$ ). The change of leaf angles distribution functions did not affect the number of parameters so as AIC values were very similar between simulation run 4 and 5, but significantly increased in simulation run 6 (not shown).

\subsection{Assessment of a simple reconstruction method for herbaceous plants parameterised from}

\section{field measurements}

In order to assess the potential of simple envelope-based reconstruction methods as practical quantitative tools, simulations were performed, simply using hand-measured traits (without the information obtained from digitising). Cylinders were used as boundary envelopes (height and maximal diameter measured for each plant in the field) whereas relative vertical leaf area

560 density distributions were inferred from whole canopy distributions measured for each species. Figure 7 presents the light interception properties at the whole plant level over the range of canopies studied. In all cases, the results were very similar to those obtained using relative size and leaf area density inferred from full 3D digitisations. For instance, model error ranged from $5.1 \%$ (pure grass-stage 2) to $17.5 \%$ (pure legume-stage 2) at LD and from $11.2 \%$

565 (pure grass-stage 2) to $24.9 \%$ (grass in mixture-stage 2) at HD. Gathering all the treatments together demonstrated that the overall predictions of light partitioning among individual plants were unbiased and quantitatively satisfactory, both at HD and LD. Model error remained small when compared to plant to plant variations in light capture $\left(\mathrm{CV}_{\mathrm{rmse}}\right.$ between $10 \%$ and $14 \%$ ) and, as previously shown, was greater at HD. The quality of the simulations 
was finally assessed by comparing measured and simulated distributions of plant leaf area by PAR irradiance classes for plants of contrasting hierarchical positions in each population (Figure 8). Distributions were not significantly different between simulated and digitized plants (KS tests p-values $>0.15$ ) in all but one cases (LD legume, stage $1, p=0.04)$. The simplified reconstructions were thus faithful enough to calculate within plant light distribution

575 for a wide range of plants structures (grass and legume plants) and in contrasting competitive situations. The light irradiance classes that were less accurately represented concerned top leaves $\left(\mathrm{I} / \mathrm{I}_{0}>=0.75\right)$ of the most dominant legume plants ( $4^{\text {th }}$ quartile of plant mass), possibly because those leaves may present non random local spatial arrangement allowing solar tracking (Travis and Reed, 1983).

\section{Discussion}

\subsection{The intensity of competition for light changed in the different plant populations studied}

The intensity of an asymmetric competition for resources, such as competition for light, as been frequently characterised using parameters accounting for size inequality among 585 individuals of the population (Weiner and Solbrig, 1984; Weiner and Thomas, 1986; Knox et al., 1989; Damgaard and Weiner, 2000). The two studied density treatments resulted in contrasted effects on the normality of mass distributions and strongly differed with respect to Gini coefficients associated to each population. Normal distributions at LD and low G' values indicated a low level of asymmetric competition (i.e. a low relative impact of larger plants on

590 the fate of smaller plants). This was corroborated by the general low canopy light interception efficiency in these treatments at the end of each of the growth period studied (i.e. LIE were therefore even lower in the course of the regrowth). At HD on the other hand almost full light interception by the canopy was rapidly achieved and high size inequality occurred in plant populations. Gini coefficients markedly increased over time. Values close to 0.5 (pure legume 
and grass in mixture) were close to those observed in crowding herbaceous plant populations (Weiner, 1985; Weiner and Thomas, 1986) and indicated that populations were clearly size structured. The intensity of competition for legumes in mixture was intermediate: it was lower than in pure stand at $\mathrm{HD}$, indicating a lower impact of the grass companion than the legume has on itself. Overall, the sparse and dense experimental canopies did produce contrasted 600 levels of competition for light.

\subsection{Accounting for heterogeneity in plant 3D structures: what matters within a canopy can} differ from isolated plants and depends on competition intensity

The question of how plant structure should be described in order to satisfactorily estimate its

605 microclimate and/or the resources available at its boundary surfaces is longstanding (Jones, 1992; Tremmel and Bazzaz, 1993; Chelle, 2005). A myriad of traits contribute to the delimitation of plant crown (e.g. branching pattern, internode length,...) and to the degree of leaf aggregation within a plant boundary envelope (e.g. branching angles, phyllotaxy, petiole length, leaf size...), determining the overall plant ability to capture light (see Valladeres and

610 Niinemets, 2007 for a review). Our results confirmed that accounting precisely for plant crown alone, even with an accurate value of crown LAD (Hull,p with homogeneously distributed actual leaf area), could lead to significantly biased estimates of light partitioning. These errors and biases more particularly concerned the plants in pluri-specific communities (subordinate grasses in particular), but were also observed in some monocultures of the two

615 architectural types represented by the grass and legume species studied, both in sparse and dense canopies. Similar results were previously shown on the case of isolated trees without neighbours (Oker-Blom and Kellomäki, 1983; Da Silva et al., 2008). Individual plant representations with homogeneous envelopes usually led to an overestimation of light capture in these studies, presumably because these representations did not account for high leaf area 
620 clumping and heterogeneous LAD within tree crowns. Recently, Duursma et al. (2011) confirmed on a large dataset of small digitised trees that, in addition to an accurate crown density representation (ratio between hull,p surface and total plant leaf area), it was necessary to account for a measure of average leaf dispersion to quantify light interception by isolated plants. Our results definitely support this assertion for plants within a canopy too. In 625 particular, we demonstrated how the consideration of foliage aggregation at a finer organisational scale (i.e. shoot scale through Hull,s simulations) could enable to remove the biases and prediction errors in light partitioning among individual plants, irrespective of plant architectural type and canopy openness.

If in some cases practical reconstruction solutions might appear tractable by directly applying 630 the 'finer scale description’ principle (Oker-Blom and Kellomäki, 1983; Sonohat et al.,2006; Da Silva et al., 2008; Louarn et al., 2008a), in many situations the number of inner scale components still exceeds any reasonable capacity of direct follow-up in the field (e.g. characterisation of all tillers in grass plants for the present study). The problem of defining an affordable plant structure thus remains largely unresolved using such a method. Instead, we 635 inferred here clumping from functions describing plant leaf area distribution along $x, y$ and $z$ axes in a 3D space. Such a representation was proposed by Ross (1981) in a theoretical study of solar radiation penetration within pure stands of plants with various planting patterns and proportions of overlapping. Similar functions (e.g; relative leaf area distribution along a vertical axis) also proved powerful to account for light partitioning between species in

640 intercropping systems (Sinoquet and Bonhomme, 1992; Sinoquet et al., 2000; Law et al., 2001; Barillot et al., 2011). The functions in the present study were empirically defined from digitised 3D plant structures and enabled to account for a large part of leaf area clumping. The simulations using it (hull,p with $x y z$ clumping) performed as well as the plant representations describing leaf aggregation at the shoot scale. Quite remarkably, it was also shown that the 
645 clumping aspects that mattered (vertical versus horizontal clumping or both) changed with the intensity of competition for light. In dense canopies, only vertical distribution of leaf area was important. Plant boundary envelopes largely overlapped under these conditions and light extinction from the top of the canopy was rapid. As expected from theoretical studies (Ross, 1981; Hikosaka et al., 2001), inter-plant competition (as accounted for by relative vertical 650 distribution of leaf area between plants) was shown to be the main driver of light partitioning whereas self-shading (as accounted for by horizontal clumping around a vertical plant axis) had little or no influence, maybe as a result of a more homogeneous LAD in plant envelope intersections. In sparse canopies on the other hand, both vertical and horizontal clumping had important roles. As compared to isolated plants for which the usual leaf dispersion parameter 655 originally proposed by Nilson (1971) for the Beer-Lambert's law seem operational to account for self-shading (Da Silva et al., 2008; Duursma et al., 2011), more details about the origin of LAD heterogeneity might thus be required for plants within a canopy. In particular, relative vertical distribution with neighbours should systematically be considered.

Finally, the comparison of plant reconstruction models we carried out also provided insights 660 on the balance to keep between relative size descriptions (i.e. accurate boundary envelopes) and leaf area properties (total plant area, leaf dispersion and leaf angles). Relative size between plants (and more particularly relative height) was shown to be crucial at HD, but had a minor role in sparse canopies. In general, the substitution of simple regular shapes such as cylinders for exact convex boundary envelopes did not result in a reduced ability to predict

665 light partitioning among plants, as long as empirical clumping functions were properly defined. The counter part was not true (as mentioned above, fine envelope description with poor leaf area properties performed poorly). Leaf angle distributions were well approximated by a generic distribution relevant to each species. Generic distributions had little or no effect on light partitioning (as already suggested by Goudriaan, 1988), but taking the wrong 
670 distribution for one or other of the species led to major discrepancies in all sparse canopies and in mixtures. Overall, the important features to be included in plant reconstructions changed according to canopy openness and competition intensity. Populations typical of a crowding situation (HD pure legumes and HD grasses in mixture) presented the approximate ranking: leaf area and vertical clumping > relative height $>$ leaf orientation $>$ other traits

675 involved in relative size and envelope definition > horizontal clumping. In sparse canopies, the traits involved in defining individual plant porosity were predominant in explaining interplant variance in light interception, an approximate ranking being: leaf area > leaf orientation $>$ horizontal clumping > relative height and vertical clumping > other traits involved in relative size and envelope definition. Wang and Jarvis (1990) pointed out a ranking in agreement with our sparse canopies results from a sensitivity analysis of their 3D model of Sitka spruce. Their analysis however concerned mono-specific stands of even-size trees only, and did not thoroughly investigate the impact of size distribution and inter-plant heterogeneity which can be high in dense size-structured plant communities.

\subsection{Simple envelope-based reconstruction methods can be quantitative tools to infer light} partitioning among individual plants in sparse and dense plant communities Because full 3D plant characterisations are obviously not usually accessible for plants within a canopy, we also assessed the performance of a simple reconstruction method (vertical cylinders with $x y z$ clumping) based on a tractable series of field measurements (plant height

690 and maximal diameter; species relative vertical leaf area density). It appeared clearly from the resulting simulations that this method could be a tool to quantify light partitioning at plant scale, in both sparse and dense canopies and for the contrasted architectural types tested (representative of typical grasses and typical erect herbaceous dicotyledons). 
Strong simplifying assumptions were assumed with respect to the clumping functions that are time consuming to calibrate: i) relative vertical leaf area distributions were the same for all plants within a species and were approximated by a triangular distribution (i.e. only the relative height of maximal LAD for the species was required for calibration) and ii) plant LAD followed a regular Gaussian distribution along $x, y$ axes. Such assumptions were supported by the fact that relative vertical distributions do not change a lot during the vegetative cycle in these herbaceous species and present a preferential leaf aggregation in the center of the plant (Ross, 1981). The solution proposed might not be generic (e.g. it cannot account for voids in envelopes), but other distributions are readily available that have proved to be versatile and powerful for this purpose (e.g. Giuliani et al., 2004).

\section{Conclusion}

Although it concerned a limited number of herbaceous plant species grown under semicontrolled conditions, the present study was able to reach several conclusions on light partitioning among individual plants that are likely to be of general value in many plant communities. Our findings change the pin point of individual plant structure characterisation

710 from an envelope definition with average leaf properties to a more thorough description of envelope content. Satisfactory characterisations of light partitioning were shown to be possible by using envelope-based plant reconstructions with empirical leaf area clumping functions. Such an approach explicitly seeks to bridge the gap between resource capture and plant functioning and could contribute to a clearer understanding of the use of different

715 resources, both above- and below-ground, by plants with different hierarchical positions in the community (Hirose and Werger, 1995; Hikosaka et al., 2003; Werger et al., 2002; Hautier et al., 2009). It could also provide the ground to build quantitative population dynamic models 
to account for short-time changes in productivity and species composition in plant communities as a result of inter-specific competition.

720

\section{Acknowledgments}

This study was supported by the Conseil Régional Poitou-Charentes (http://www.poitoucharentes.fr), by Agropolis Foundation (ALEA Project) and by the AIP INRA-INRIA (Alinea Project). We would like to thank S. Carre, A. Eprinchard, A. Philiponneau and V. Dunoyer for their help with the experiments and A. Escobar-Gutiérrez for helpful discussions.

\section{References}

Adam, B., Sinoquet, H., Godin, C., Donès, N., 1999. 3A-Software for the acquisition of plant architecture. Version 2.0. UMR PIAF INRA-UBP, Clermont-Ferrand, France.

Barillot, R., Louarn, G., Escobar-Gutiérrez, A.J., Huynh, P., Combes, D., 2011. How good is the turbid medium-based approach for accounting for light partitioning in contrasted grasslegume intercropping systems? Ann. Bot., 108(6) 1013-1024.

Berger, U., Piou, C., Schiffers, K., Grimm, V., 2008. Competition among plants: Concepts, individual-based modelling approaches, and a proposal for a future research strategy. Persp. Plant Ecol. 9 (3-4): 121-135.

Boffey, T.B., Veevers, A., 1977. Balanced designs for two-component competition experiments. Euphytica 26: 481-484.

Burnham K.P., Anderson, D.R., 2002. Model Selection and multimodel inference. A practical information - Theoric approach. 2nd Edition. Ed. Springer, 496 p.

740 Campbell G.S., Norman, J.M., 2000. An introduction to environmental biophysics. New York, NY, USA, Springer Verlag. 
Cescatti, A., Zorer, R. 2003. Structural acclimation and radiation regime of silver fir (Abies alba Mill.) shoots along a light gradient. Plant Cell Environ. 26: 429-442.

Chave, J., 1999. Study of structural, successional and spatial patterns in tropical rain forests 745 using TROLL, a spatially explicit forest model. Ecol. Model. 124(2-3): 233-254.

Chelle, M., Andrieu, B., 1998. The nested radiosity model for the distribution of light within plant canopies. Ecol. Model. 111(1): 75-91.

Chelle, M., 2005. Phylloclimate or the climate perceived by individual plant organs: What is it? How to model it? What for? New Phytol. 166(3): 781-790.

750 Cluzeau, C., Dupouey, J.L., Courbaud, B., 1995. Polyhedral representation of crown shape. A geometric tool for growth modelling. Ann. Forest. Sci. 52: 297-306.

Da Silva, D., Boudon, F., Godin, C., Sinoquet, H., 2008. Multiscale framework for modelling and analysing light interceprion by trees. Multiscale Model. Simul. 7(2): 910-933.

Damgaard, C., 2004. Evolutionary ecology of plant-plant interactions - An empirical

755 modelling approach. Aarhus University Press, Aarhus, DK.

Damgaard, C., Weiner, J., 2000. Describing inequality in plant size or fecundity. Ecology $81: 1139-1142$.

Duursma, R.A., Falster, D.S., Valladares, F., Sterck, F.J., Pearcy, R.W., Lusk, C.H., Sendall, K.M., Nordenstahl, M., Houter, N.C., Atwell, B.J., Kelly, N., Kelly, J.W.G., Liberloo, M.,

760 Tissue, D.T., Medlyn, B.E., Ellsworth, D.S., 2012. Light interception efficiency explained by two simple variables: a test using a diversity of small- to medium-sized woody plants. New Phytol. 193(2): 397-408.

Giuliani, R., Magnanini, E., Nerozzi, F., Muzzi, E., Sinoquet, H., 2005. Canopy probabilistic reconstruction inferred from Monte Carlo point-intercept leaf sampling. Agr. Forest. Meteorol. 128(1-2): 17-32. 
Godin, C., Costes, E., Sinoquet, H., 1999. A Method for Describing Plant Architecture which Integrates Topology and Geometry. Ann. Bot. 84(3): 343-357.

Gosse, G., Lemaire, G., Chartier, M., Balfourier, F., 1988. Structure of a lucerne population (Medicago sativa L.) and dynamics of stem competition for light during regrowth. J. Appl. Ecol. 25, 609-617.

Goudriaan, J., 1988. The bare bones of leaf angle distribution in radiation models for canopy photosynthesis and energy exchange. Agr. Forest. Meteorol. 43: 155-169.

Grime, J.P., 1979. Plant Strategies and Vegetation Processes, John Wiley \& Sons

Hara, T., 1988. Dynamics of size structure in plant populations. Trends Ecol. Evol. 3(6): 129133.

Hara T., Wyszomirski, T., 1994. Competitive Asymmetry Reduces Spatial Effects on SizeStructure Dynamics in Plant Populations. Ann. Bot. 73 (3): 285-297

Harper, J.L., 1961. Approaches to the study of plant competition. In: Mechanisms in biological competition, Milthorpe F.L. (Ed.) Symp. Soc. Exp. Biol., 15: 1-39.

780 Harper, J.L., 1977. Population Biology of Plants. Academic Press, New York.

Hautier, Y., Niklaus, P.A., Hector, A., 2009. Competition for light causes plant biodiversity loss after eutrophication. Science 324(5927): 636-638.

Hikosaka, K., Sudoh, S., Hirose, T., 1999. Light acquisition and use by individuals competing in a dense stand of an annual herb, Xanthium canadense. Oecologia 118(3): 388-396.

Hikosaka, K., H. Nagashima, Harada, Y., Hirose, T., 2001. A simple formulation of interaction between individuals competing for light in a monospecific stand. Funct. Ecol. 15(5): 642-646.

Hikosaka, K., Yamano, T., Nagashima, H., Hirose, T., 2003. Light-acquisition and use of individuals as influenced by elevated $\mathrm{CO} 2$ in even-aged monospecific stands of

790 Chenopodium album. Funct. Ecol. 17(6): 786-795. 
Hirose, T., Werger, M.J.A., 1995. Canopy structure and photon flux partitioning among species in a herbaceous plant community. Ecology 76:466-474.

Johnson, R.S., Lakso, A.N., 1991. Approaches to modelling light interception in orchards. HortScience 26: 1002-1004.

Jones, H.G., 1992. Plants and Microclimate: A Quantitative Approach to Environmental Plant Physiology, second ed. Cambridge University Press, UK.

Keddy, P.A., 2001. Competition. 2nd Edition, Kluwer Academic Publishers.

Knox, R.G., Peet, R.K., Christiensen, N.L., 1989. Population dynamics in loblolly pine stands: changes in skewness and size inequality. Ecology 70:1153-1166.

800 Law, B.E., Cescatti, A., Baldochi, D.D., 2001. Leaf area distribution and radiative transfer in open-canopy forest: implications for mass energy exchange. Tree Physiol. 21: 777-787.

Lomnicki, A., 1988. Population ecology of individuals. Princeton University Press, Princeton, New Jersey, USA.

Louarn, G., Lecoeur, J., Lebon, E., 2008a. A Three-dimensional Statistical Reconstruction 805 Model of Grapevine (Vitis vinifera) Simulating Canopy Structure Variability within and between Cultivar/Training System Pairs. Ann. Bot. 101: 1167-1184.

Louarn, G., Dauzat, J., Lecoeur J., Lebon, E., 2008b. Influence of trellis system and shoot positioning on light interception and distribution in two grapevine cultivars with different architectures: an original approach based on 3D canopy modelling. Austral. J. Grape Wine Res. 14(3): 143-152.

Louarn, G., Corre-Hellou, G., Fustec, J., Lô-Pelzer, E., Julier, B., Litrico, I., Hinsinger, P., Lecomte, C., 2010. Ecological and physiological determinants of the productivity and stability of grass-legume mixtures. Innov. Agron. 11: 79-99. 
Malézieux, E., Crozat, Y., Dupraz, C., Laurans, M., Makowski, D., Ozier-Lafontaine, H., 815 Rapidel, B., de Tourdonnet, S., Valantin-Morison, M., 2009. Mixing plant species in cropping systems: concepts, tools and models. A review. Agron. Sustain. Dev. 29(1): 43-62. Monsi, M., Saeki, T., 1953. Über den Lichtfaktor in den Pflanzengesellschaften und seine Bedeutung für die Stoffproduktion. Jap. J. Bot. 14: 22-52.

Moon, P., Spencer, D.E., 1942. Illumination from a non-uniform sky. T. Illum. Eng. Soc. 37: 707-712.

Mõttus, M., Sulev, M., Lang, M., 2006. Estimation of crown volume for a geometric radiation model from detailed measurements of tree structure. Ecol. Model. 198(3-4): 506-514.

Nilson, T., 1971. A theoretical analysis of the frequency of gaps in plant stands. Agric. Meteorol. 8: 25-38.

825 Norman, J.M., Welles, J.M., 1983. Radiative Transfer in an Array of Canopies. Agron. J. 75(3): 481-488.

Obeid, M., Machin, D., Harper, J. L., 1967. Influence of density on plant to plant variation in fibre flax, Linum usitatissimum L. Crop Sci. 7:471-73

Oker-Blom, P., Kellomaki, S., 1983. Effect of grouping of foliage on within-stand and within 830 crown light regimes: comparison of radiation and grouping canopy models. Agric. Meteorol. 28:143-155.

Pearcy, R.W., Yang, W., 1996. A three-dimensional crown architecture model for assessment of light capture and carbon gain by understory plants. Oecologia, 108: 1-12.

Pradal, C., Dufour-Kowalski, S., Boudon, F., Fournier, C., Godin, C., 2008. OpenAlea: a 835 visual programming and component-based software platform for plant modelling. Funct. Plant Biol. 35(10): 751-760.

Pradal, C., Boudon, F., Nouguier, C., Chopard, J., Godin, C., 2009. PlantGL: a Python-based geometric library for 3D plant modelling at different scales. Graphical Models 71(1): 1-21. 
Prévot, L., Aries, F., Monestiez, P., 1991. Modélisation de la structure géométrique du maïs. Agronomie 11: 491-503.

Ross, J.K., 1981. The radiation regime and architecture of plant stands. Dr. W. Junk Publisher, The Hague.

Rimmington, G.M., 1984. A model of the effect of interspecies competition for light on drymatter production. Austral. J. Plant Physiol. 11: 277-286.

845 Schwinning, S., Weiner, J., 1998. Mechanisms determining the degree of size asymmetry in competition among plants. Oecologia 113(4): 447-455.

Sen, A., 1973. On economic inequality. Clarendon, Oxford.

Sinoquet, H., Bonhomme, R., 1992. Modeling radiative transfer in mixed and row intercropping systems. Agr. Forest. Meteorol. 62: 219-240.

850 Sinoquet, H., Andrieu, B., 1993. The geometrical structure of plant canopies: Characterization and direct measurements methods. In: Varlet-Grancher, C., Bonhomme, R. and Sinoquet, H Editors, 1993. Crop structure and light microclimate: characterization and applications INRA, Paris, pp. 131-158.

Sinoquet, H., Rivet, P., 1997. Measurement and visualisation of the architecture of an adult tree based on a three-dimensional digitizing device. Trees 11:265-270.

Sinoquet, H., Rakocevic, M., Varlet-Grancher, C., 2000. Comparison of models for daily light partitionning in multispecies canopies. Agr. Forest. Meteorol. 101: 251-263.

Sonohat, G., Sinoquet, H., Varlet-Grancher, C., Rakocevic, M., Jacquet, A., Simon, J.-C., Adam, B., 2002. Leaf dispersion and light partitioning in three-dimensionally digitized tall 860 fescue-white clover mixtures. Plant Cell Environ. 25(4): 529-538.

Sonohat, G., Sinoquet, H., Kulandaivelu, V., Combes, D., Lescourret, F., 2006. Threedimensional reconstruction of partially 3D-digitized peach tree canopies. Tree physiol. 26(3): 337-351. 
Tilman, D., 1988. Plant strategies and the dynamics and structure of plant communities.

Travis, R.L., Reed, R., 1983. The Solar Tracking Pattern in a Closed Alfalfa Canopy. Crop Sci. 23(4): 664-668.

Tremmel, D.C., Bazzaz, F.A., 1993. How neighbour canopy architecture affects target plant performance. Ecology 74(7): 2114-2124.

870 Valladares, F., Niinemets, Ü., 2007. The architecture of plant crowns: from design rules to light capture and performance. In Functional Plant Ecology, ed. FI Pugnaire, F Valladares, New York: CRC/Taylor \& Francis Group. pp. 101-150.

Wang, Y.P., Jarvis, P.G., 1990. Influence of crown structural properties on PAR absorption, photosynthesis, and transpiration in Sitka spruce: application of a model (MAESTRO). Tree $875 \quad$ Physiol. 7 (1-2-3-4): 297-316.

Weiner, J., 1985. Size Hierarchies in Experimental Populations of Annual Plants. Ecology 66(3): 743-752.

Weiner, J., Solbrig, O.T., 1984. The meaning and measurement of size hierarchies in plant populations. Oecologia 61(3): 334-336.

880 Weiner, J., Thomas, S.C., 1986. Size Variability and Competition in Plant Monocultures. Oikos 47(2): 211-222.

Werger, M.J.A., Hirose, T., During, H.J., Heil, G.W., Hikosaka, K., Ito, T., Nachinshonhor, U.G., Nagamatsu, D., Shibasaki, K., Takatsuki, S., van Rheenen, J.W., Anten, N.P.R., 2002. Light partitioning among species and species replacement in early successional 885 grasslands. Journal of Vegetation Science 13(5): 615-626. 
Table captions

890 Table 1: Envelope-based models tested and corresponding boundary envelope traits in the 3D reconstructions

Table 2: Within envelope leaf properties used in the six simulations run in each of the envelope-based models

895

Table 3: Comparison of PAR interception integrated at the plant scale between digitisations and the different envelope-based models tested for the simulation run 1 (uniform LAD, all plants with the same leaf area). Stage 1 and 2 stand for the two measurement periods studied. Data are presented through the slope $(a)$, coefficient of determination $\left(\mathrm{r}^{2}\right)$ and errors $\left(\mathrm{CV}_{\mathrm{rmse}}\right)$ 900 of the relationship for each studied stand. The ${ }_{\mathrm{i}}$ subscript indicates a significant intercept in the relationship whereas ${ }_{n s}$ indicates a non-significant correlation between measured and simulated values.

Table 4: Comparison of PAR interception integrated at the plant scale between digitisations and the different envelope-based models tested for the simulation run 2 (uniform LAD within envelopes, total leaf area defined from plant-to-plant measurements). Stage 1 and 2 stand for the two measurement periods studied. Data are presented through the slope $(a)$, coefficient of determination $\left(\mathrm{r}^{2}\right)$ and errors $\left(\mathrm{CV}_{\mathrm{rmse}}\right)$ of the relationship for each studied stand. The ${ }_{\mathrm{i}}$ subscript indicates a significant intercept in the relationship whereas ns indicates a nonsignificant correlation between measured and simulated values.

Table 5: Impact of leaf area clumping on the performance of envelope-based models to estimate PAR interception at the plant scale within a canopy. Vertical ( $z$ ) and/or horizontal 
(xyz) clumping within the envelopes are presented for Hull,p and Cylinder envelopes

915 (simulation runs 3 and 4). Hull,p results for uniform LAD (simulation run 2) stand for a reference without clumping, whereas Hull,s represent a reference considering clumping at a finer organisation scale than plan scale (i.e. shoot). Data are presented through the slope $(a)$, coefficient of determination $\left(\mathrm{r}^{2}\right)$ and errors $\left(\mathrm{CV}_{\text {rmse }}\right)$ of the relationship between measured and simulated plant light interception values for each studied stand.

920

Table 6: Impact of leaf elevation distributions on the performance of envelope-based models to estimate PAR interception at the plant scale within a canopy. The erectophil (erect) and plagiophil (plagio) distributions used were defined in eqn 2-3. Results are presented for Hull,p and Cylinder envelopes (simulation runs 5 and 6) through the slope (a), coefficient of 925 determination $\left(\mathrm{r}^{2}\right)$ and errors $\left(\mathrm{CV}_{\text {rmse }}\right)$ of the relationship between measured and simulated plant light interception values for each studied stand. 
Figure captions:

930

Figure 1: Representation of a) high density (HD) and b) low density (LD) digitised 3D stands at the two measurement periods studied (stages 1 and 2). In mixtures, grasses are represented in red.

935 Figure 2: Top views (top) and lateral views (bottom) of the plant boundary envelopes generated by the different envelope-based models test in the case of a pure grass stand at HD. The colour chart is used to identify individual plants.

Figure 3: Distribution of the dry mass of plants for pure legume stands (top) and grass-legume 940 mixtures (bottom) at the two measurement periods studied (stages 1 and 2). The Gini coefficient (G') and p-values of the Kolmogorov-Smirnov test are indicated for grass (gr) and legume (leg) populations separately ( $\mathrm{n}=100$ at HD; $\mathrm{n}=60$ at LD).

Figure 4: Light partitioning at the canopy level between grass, legume and soil components 945 calculated for each of the 12 digitised 3D stands.

Figure 5: Two examples of relationships between intercepted PAR integrated at the plant scale using digitisations and using an envelope-based model. Data are summarised through the slope $(a)$, coefficient of determination $\left(\mathrm{r}^{2}\right)$ and model errors (RMSE, $\left.\mathrm{CV}_{\mathrm{rmse}}\right)$ of the 950 relationship for each situation. The plain line represents the 1:1 bisector whereas the dotted line represents the correlations between measured and simulated intercepted PAR. 
Figure 6: Comparison of models on the basis of the Akaike's Information Criterion for simulation runs 1 to 4 . Data are presented for four contrasting legume (LD stage1, a; HD stage 2, b) and grass (LD mixture stage 1, c; HD mixture stage 2) situations. Horizontal lines stand for AIC values of the null model in run 1 (plain gray line; all the plants represented with the same 3D structure and total leaf area), and run 2 (dashed gray line, all the plants represented with the same 3D structure and with their actual leaf area).

960 Figure 7: Relationships between measured and simulated PAR interception at plant scales when using field measurements for individual plant reconstructions. The reconstructions used cylinder boundary envelopes with $x y z$ clumping and leaf angle distributions from the literature. HD (a) and LD (b) are presented in separate panels. The plain line represents the 1:1 bisector. Vertical bars indicate the standard deviation of simulations $(\mathrm{n}=10)$.

965

Figure 8: Distributions of plant leaf area by PAR irradiance classes for simulated (charts) and measured (lines) 3D structures. Data are presented for four contrasting legume (LD stage1, a; HD stage 2, b) and grass (LD mixture stage 1, c; HD mixture stage 2) situations and for plants in the four quartiles of biomass in each population (see Fig. 3). Figures indicate the p-values of the Kolmogorov-Smirnov test verifying whether the two underlying one-dimensional probability distributions differ. 
975

Supplementary material

Table A

Table A: Comparison of PAR interception integrated at the plant scale between digitisations 980 and the different envelope-based models tested for the simulation run 3 and 4. Data are presented through the slope $(a)$, coefficient of determination $\left(\mathrm{r}^{2}\right)$ and errors $\left(\mathrm{CV}_{\mathrm{rmse}}\right)$ of the relationship for each studied stand.

Fig A: Relationship between alfalfa foliole lengths derived from a two point digitisation and 985 direct measurement of foliole length with a ruler. 
Table 1

\begin{tabular}{llllccccc}
\hline Abbreviation & Envelope geometry & Scale & \multicolumn{5}{c}{ Traits considered in boundary envelopes } & References \\
& & & Height & Max Diameter & Asymetry X & Asymetry Y & Asymetry Z \\
\hline Hull,s & Convex Hull & Shoot & $\mathrm{x}$ & $\mathrm{x}$ & $\mathrm{x}$ & $\mathrm{x}$ & $\mathrm{x}$ & Da Silva et al. 2008 \\
Hull,p & Convex Hull & Plant & $\mathrm{x}$ & $\mathrm{x}$ & $\mathrm{x}$ & $\mathrm{x}$ & $\mathrm{x}$ & Cluzeau, Dupouey \& Courbaud 1995 \\
Ellipsoid & Ellipsoid & Plant & $\mathrm{x}$ & $\mathrm{x}$ & $\mathrm{x}$ & $\mathrm{x}$ & - & Mottus et al. 2006 \\
Cylinder & Cylinder & Plant & $\mathrm{x}$ & $\mathrm{x}$ & - & - & - & Chave 1999 \\
Tessel & Tesselassion prism & Plant & $\mathrm{x}$ & - & - & - & - & Hirose \& Werger 1995; Hikosaka, Sudoh \& Hirose 1999 \\
Null model & No model fit & Plant & - & - & - & - & - & \\
\hline
\end{tabular}


Table 2

Table 2

\begin{tabular}{lccc}
\hline Simulations & Plant leaf area & Leaf area clumping & Leaf angle distributions \\
\hline 1 & uniform & uniform & digit \\
2 & digit & uniform & digit \\
3 & digit & uniform along xy, digit along z & digit \\
4 & digit & digit along xyz & digit \\
5 & digit & digit along xyz & theoretical distributions \\
6 & digit & digit along $x y z$ & unpaired theoretical distributions \\
\hline
\end{tabular}

5

10

15 
Table 3

\begin{tabular}{|c|c|c|c|c|c|c|c|c|c|c|c|c|c|}
\hline & \multirow{3}{*}{ Envelope } & \multicolumn{6}{|c|}{$\mathrm{HD}$} & \multicolumn{6}{|c|}{ LD } \\
\hline & & \multicolumn{3}{|c|}{ stage 1} & \multicolumn{3}{|c|}{ stage 2} & \multicolumn{3}{|c|}{ stage 1} & \multicolumn{3}{|c|}{ stage 2} \\
\hline & & $\mathrm{a}$ & $r^{2}$ & $\mathrm{CV}_{\text {rmse }}(\%)$ & $\mathrm{a}$ & $r^{2}$ & $\mathrm{CV}_{\text {rmse }}(\%)$ & $\mathrm{a}$ & $r^{2}$ & $\mathrm{CV}_{\text {rmse }}(\%)$ & $\mathrm{a}$ & $r^{2}$ & $\mathrm{CV}_{\text {rmse }}(\%)$ \\
\hline \multirow{5}{*}{$\begin{array}{l}\text { Pure } \\
\text { legume }\end{array}$} & Null model & $0.14^{i}$ & $0.16^{\mathrm{ns}}$ & 30.9 & $0.07^{i}$ & $0.09^{\mathrm{ns}}$ & 45.8 & $0.05^{i}$ & $0.13^{\mathrm{ns}}$ & 33.8 & $0.10^{i}$ & $0.17^{\mathrm{ns}}$ & 32.1 \\
\hline & Tessel & $0.49^{i}$ & 0.53 & 23.2 & $0.38^{i}$ & 0.52 & 44.9 & $0.12^{i}$ & 0.48 & 31.8 & $0.29^{i}$ & 0.32 & 37.8 \\
\hline & Cylinder & 0.94 & 0.53 & 19.2 & $0.45^{i}$ & 0.66 & 40.9 & $0.13^{i}$ & 0.42 & 32.2 & $0.40^{i}$ & 0.42 & 35.5 \\
\hline & Ellipsoid & 0.94 & 0.60 & 18.0 & $0.47^{i}$ & 0.65 & 38.6 & $0.21^{i}$ & 0.52 & 30.0 & $0.43^{i}$ & 0.46 & 34.4 \\
\hline & Hull,p & 0.93 & 0.45 & 20.1 & $0.50^{i}$ & 0.69 & 40.7 & $0.16^{i}$ & 0.42 & 31.9 & $0.51^{i}$ & 0.62 & 26.6 \\
\hline \multirow{5}{*}{$\begin{array}{l}\text { Pure } \\
\text { grass }\end{array}$} & Null model & $0.20^{i}$ & $0.04^{\mathrm{ns}}$ & 30.5 & $-0.21^{i}$ & $0.11^{\mathrm{ns}}$ & 37.2 & $0.11^{i}$ & $0.18^{\mathrm{ns}}$ & 18.0 & $0.02^{i}$ & $0.01^{\mathrm{ns}}$ & 19.5 \\
\hline & Tessel & $0.41^{i}$ & $0.06^{\mathrm{ns}}$ & 40.8 & $-0.46^{i}$ & $0.17^{\mathrm{ns}}$ & 50.1 & $0.30^{i}$ & $0.14^{\mathrm{ns}}$ & 17.7 & $0.11^{i}$ & $0.12^{\mathrm{ns}}$ & 18.9 \\
\hline & Cylinder & $0.38^{i}$ & $0.04^{\mathrm{ns}}$ & 47.7 & $-0.40^{i}$ & $0.16^{\mathrm{ns}}$ & 48.3 & $0.14^{i}$ & $0.15^{\mathrm{ns}}$ & 21.5 & $0.14^{i}$ & $0.16^{\mathrm{ns}}$ & 18.5 \\
\hline & Ellipsoid & $0.40^{i}$ & $0.04^{\mathrm{ns}}$ & 51.0 & $-0.47^{i}$ & $0.16^{\mathrm{ns}}$ & 52.4 & $0.23^{i}$ & 0.35 & 18.6 & $0.15^{i}$ & $0.15^{\mathrm{ns}}$ & 18.7 \\
\hline & Hull,p & $0.54^{i}$ & 0.21 & 26.9 & $0.06^{i}$ & $0.00^{\mathrm{ns}}$ & 36.4 & $0.35^{i}$ & 0.41 & 16.1 & $0.14^{i}$ & $0.13^{\mathrm{ns}}$ & 21.4 \\
\hline \multirow{5}{*}{$\begin{array}{c}\text { Legume } \\
\text { in } \\
\text { mixture }\end{array}$} & Null model & $0.05^{i}$ & $0.01^{\text {ns }}$ & 22.2 & $0.12^{i}$ & $0.07^{\mathrm{ns}}$ & 33.3 & $0.00^{i}$ & $0.00^{\mathrm{ns}}$ & 12.1 & $-0.09^{i}$ & $0.07^{\mathrm{ns}}$ & 17.3 \\
\hline & Tessel & $0.08^{i}$ & $0.02^{\mathrm{ns}}$ & 24.5 & $0.22^{i}$ & $0.13^{n s}$ & 30.2 & $0.08^{i}$ & $0.04^{\mathrm{ns}}$ & 11.6 & $-0.08^{i}$ & $0.03^{n s}$ & 18.1 \\
\hline & Cylinder & $0.21^{i}$ & $0.09^{\text {ns }}$ & 20.5 & $0.35^{i}$ & 0.26 & 26.7 & $0.10^{i}$ & $0.07^{\mathrm{ns}}$ & 12.2 & $0.09^{i}$ & $0.03^{n s}$ & 15.5 \\
\hline & Ellipsoid & $0.23^{i}$ & $0.11^{\mathrm{ns}}$ & 19.3 & $0.38^{i}$ & 0.28 & 27.1 & $0.19^{i}$ & 0.20 & 11.1 & $0.09^{i}$ & $0.02^{\mathrm{ns}}$ & 15.4 \\
\hline & Hull,p & $0.34^{i}$ & 0.22 & 17.6 & 0.97 & 0.73 & 15.5 & $0.18^{i}$ & 0.23 & 10.4 & $0.19^{i}$ & $0.15^{\mathrm{ns}}$ & 12.9 \\
\hline \multirow{5}{*}{$\begin{array}{l}\text { Grass } \\
\text { in } \\
\text { mixture }\end{array}$} & Null model & 1.85 & $0.12^{\mathrm{ns}}$ & 65.6 & $-0.40^{i}$ & $0.02^{\mathrm{ns}}$ & 54.7 & $0.29^{i}$ & 0.49 & 19.2 & $0.01^{i}$ & $0.00^{\mathrm{ns}}$ & 35.6 \\
\hline & Tessel & 2.10 & $0.14^{\mathrm{ns}}$ & 59.2 & $-0.58^{i}$ & $0.04^{\mathrm{ns}}$ & 52.0 & $0.76^{i}$ & 0.66 & 12.7 & $0.29^{i}$ & $0.06^{\mathrm{ns}}$ & 31.2 \\
\hline & Cylinder & 2.24 & $0.13^{\mathrm{ns}}$ & 59.9 & $-0.35^{i}$ & $0.06^{\mathrm{ns}}$ & 40.6 & $0.77^{i}$ & 0.48 & 19.1 & $0.24^{i}$ & $0.05^{\mathrm{ns}}$ & 33.5 \\
\hline & Ellipsoid & 1.98 & $0.14^{\text {ns }}$ & 55.4 & $-0.45^{i}$ & $0.08^{\mathrm{ns}}$ & 41.8 & $0.87^{i}$ & 0.53 & 18.3 & $0.26^{i}$ & $0.05^{\mathrm{ns}}$ & 30.9 \\
\hline & Hull,p & 1.36 & 0.25 & 32.1 & $0.20^{i}$ & $0.06^{\mathrm{ns}}$ & 30.1 & $0.67^{i}$ & 0.55 & 16.6 & $0.23^{i}$ & $0.03^{\mathrm{ns}}$ & 27.6 \\
\hline
\end{tabular}


Table 4

\begin{tabular}{|c|c|c|c|c|c|c|c|c|c|c|c|c|c|}
\hline & \multirow{3}{*}{ Envelope } & \multicolumn{6}{|c|}{$\mathrm{HD}$} & \multicolumn{6}{|c|}{ LD } \\
\hline & & \multicolumn{3}{|c|}{ stage 1} & \multicolumn{3}{|c|}{ stage 2} & \multicolumn{3}{|c|}{ stage 1} & \multicolumn{3}{|c|}{ stage 2} \\
\hline & & $\mathrm{a}$ & $r^{2}$ & $\mathrm{CV}_{\text {rmse }}(\%)$ & $\mathrm{a}$ & $r^{2}$ & $\mathrm{CV}_{\text {rmse }}(\%)$ & $\mathrm{a}$ & $r^{2}$ & $\mathrm{CV}_{\text {rmse }}(\%)$ & $\mathrm{a}$ & $r^{2}$ & $\mathrm{CV}_{\text {rmse }}(\%)$ \\
\hline \multirow{5}{*}{$\begin{array}{l}\text { Pure } \\
\text { legume }\end{array}$} & Null model & $0.48^{i}$ & 0.44 & 30.3 & 0.74 & 0.55 & 39.3 & 1.05 & 0.99 & 5.5 & 0.90 & 0.62 & 23.4 \\
\hline & Tessel & 0.95 & 0.60 & 22.6 & 0.81 & 0.79 & 29.8 & 1.05 & 0.99 & 4.9 & 0.92 & 0.71 & 21.0 \\
\hline & Cylinder & 0.98 & 0.71 & 22.9 & 0.97 & 0.95 & 16.0 & 1.03 & 0.99 & 4.0 & 0.98 & 0.82 & 18.9 \\
\hline & Ellipsoid & 0.98 & 0.76 & 21.3 & 0.96 & 0.96 & 14.9 & 1.04 & 0.99 & 4.7 & 0.98 & 0.84 & 17.7 \\
\hline & Hull,p & 0.97 & 0.80 & 18.1 & 1.00 & 0.93 & 20.0 & 1.02 & 0.99 & 3.1 & 0.99 & 0.94 & 10.9 \\
\hline \multirow{5}{*}{$\begin{array}{l}\text { Pure } \\
\text { grass }\end{array}$} & Null model & 0.98 & 0.46 & 18.8 & 0.97 & 0.21 & 22.2 & 1.00 & 0.93 & 5.4 & 1.04 & 0.95 & 5.4 \\
\hline & Tessel & 0.99 & 0.30 & 32.8 & 0.93 & $0.16^{\mathrm{ns}}$ & 29.2 & 1.00 & 0.93 & 7.7 & 1.05 & 0.94 & 5.5 \\
\hline & Cylinder & 1.00 & 0.31 & 38.5 & 0.97 & 0.20 & 27.4 & 1.00 & 0.85 & 13.5 & 1.06 & 0.93 & 7.0 \\
\hline & Ellipsoid & 1.01 & 0.28 & 41.0 & 0.98 & 0.18 & 27.4 & 1.04 & 0.83 & 15.0 & 1.06 & 0.94 & 6.7 \\
\hline & Hull,p & 1.00 & 0.72 & 20.3 & 1.01 & 0.66 & 19.6 & 1.02 & 0.91 & 9.8 & 1.05 & 0.85 & 8.4 \\
\hline \multirow{5}{*}{$\begin{array}{l}\text { Legume } \\
\text { in } \\
\text { mixture }\end{array}$} & Null model & $0.42^{i}$ & 0.52 & 16.5 & $0.33^{i}$ & 0.41 & 26.3 & 1.06 & 0.92 & 5.4 & 0.98 & 0.73 & 6.3 \\
\hline & Tessel & 0.89 & 0.46 & 15.6 & $0.42^{i}$ & 0.42 & 23.5 & 1.05 & 0.90 & 5.2 & 0.98 & 0.67 & 7.6 \\
\hline & Cylinder & 0.95 & 0.42 & 13.5 & 0.96 & 0.49 & 21.2 & 1.09 & 0.89 & 7.6 & 1.05 & 0.75 & 7.0 \\
\hline & Ellipsoid & 0.95 & 0.39 & 12.7 & 0.96 & 0.57 & 17.7 & 1.06 & 0.87 & 6.0 & 1.05 & 0.69 & 8.1 \\
\hline & Hull,p & 0.97 & 0.69 & 10.4 & 1.02 & 0.93 & 10.7 & 1.04 & 0.92 & 4.4 & 1.03 & 0.81 & 7.3 \\
\hline \multirow{5}{*}{$\begin{array}{l}\text { Grass } \\
\text { in } \\
\text { mixture }\end{array}$} & Null model & 2.85 & 0.64 & 64.9 & $0.58^{i}$ & $0.13^{\mathrm{ns}}$ & 51.0 & 1.19 & 0.93 & 16.5 & 1.54 & 0.93 & 35.1 \\
\hline & Tessel & 2.21 & 0.35 & 57.1 & $0.31^{i}$ & $0.03^{\mathrm{ns}}$ & 38.3 & 1.10 & 0.86 & 11.2 & 1.45 & 0.87 & 30.4 \\
\hline & Cylinder & 2.34 & 0.38 & 56.0 & $0.22^{i}$ & $0.02^{\mathrm{ns}}$ & 36.8 & 1.12 & 0.80 & 15.7 & 1.51 & 0.84 & 33.3 \\
\hline & Ellipsoid & 1.97 & 0.37 & 49.3 & $0.45^{i}$ & $0.14^{\mathrm{ns}}$ & 31.6 & 1.15 & 0.79 & 16.1 & 1.45 & 0.81 & 30.7 \\
\hline & Hull,p & 1.37 & 0.70 & 27.0 & 1.18 & 0.38 & 23.2 & 1.10 & 0.86 & 11.4 & 1.38 & 0.78 & 27.1 \\
\hline
\end{tabular}


Table 5

\begin{tabular}{|c|c|c|c|c|c|c|c|c|c|c|c|c|c|c|}
\hline & \multirow{3}{*}{ Envelop } & \multirow{3}{*}{$\begin{array}{l}\text { Leaf } \\
\text { dist. }\end{array}$} & \multicolumn{6}{|c|}{$\mathrm{HD}$} & \multicolumn{6}{|c|}{ LD } \\
\hline & & & \multicolumn{3}{|c|}{ stage 1} & \multicolumn{3}{|c|}{ stage 2} & \multicolumn{3}{|c|}{ stage 1} & \multicolumn{3}{|c|}{ stage 2} \\
\hline & & & $a$ & $r^{2}$ & $\mathrm{CV}_{\text {rmse }}(\%)$ & $\mathrm{a}$ & $r^{2}$ & $\mathrm{CV}_{\text {rmse }}(\%)$ & $a$ & $r^{2}$ & $\mathrm{CV}_{\text {rmse }}(\%)$ & $a$ & $r^{2}$ & $\mathrm{CV}_{\text {rmse }}(\%)$ \\
\hline \multirow{6}{*}{$\begin{array}{l}\text { Pure } \\
\text { legume }\end{array}$} & Hull,p & uniform & 0.97 & 0.80 & 18.1 & 1.00 & 0.93 & 20.0 & 1.02 & 0.99 & 3.1 & 0.99 & 0.94 & 10.9 \\
\hline & Hull,s & uniform & 1.00 & 0.88 & 16.0 & 0.98 & 0.98 & 11.0 & 0.95 & 0.99 & 5.4 & 0.98 & 0.95 & 12.4 \\
\hline & Hull,p & z & 0.97 & 0.83 & 14.3 & 1.06 & 0.95 & 18.9 & 1.02 & 0.99 & 4.0 & 1.04 & 0.97 & 9.6 \\
\hline & Cylinder & $z$ & 0.98 & 0.85 & 14.9 & 1.03 & 0.97 & 13.8 & 1.05 & 0.98 & 5.5 & 1.02 & 0.90 & 16.4 \\
\hline & Hull,p & $x y z$ & 0.98 & 0.82 & 17.6 & 1.04 & 0.95 & 18.4 & 0.96 & 0.97 & 6.0 & 1.00 & 0.96 & 9.7 \\
\hline & Cylinder & $x y z$ & 0.97 & 0.84 & 15.1 & 0.99 & 0.98 & 10.3 & 0.99 & 0.97 & 5.0 & 1.00 & 0.89 & 16.1 \\
\hline \multirow{6}{*}{$\begin{array}{l}\text { Pure } \\
\text { grass }\end{array}$} & Hull,p & uniform & 1.00 & 0.72 & 20.3 & 1.01 & 0.66 & 19.6 & 1.02 & 0.91 & 9.8 & 1.05 & 0.85 & 8.4 \\
\hline & Hull,s & uniform & 1.00 & 0.87 & 10.4 & 1.00 & 0.88 & 10.9 & 0.99 & 0.98 & 3.4 & 0.99 & 0.99 & 2.2 \\
\hline & Hull,p & z & 1.00 & 0.89 & 10.3 & 1.02 & 0.84 & 13.3 & 1.02 & 0.97 & 4.7 & 1.05 & 0.95 & 6.2 \\
\hline & Cylinder & $z$ & 1.00 & 0.90 & 10.2 & 1.01 & 0.92 & 7.4 & 1.02 & 0.97 & 4.7 & 1.05 & 0.95 & 6.4 \\
\hline & Hull,p & $x y z$ & 1.00 & 0.87 & 11.4 & 1.01 & 0.91 & 9.2 & 1.01 & 0.98 & 3.6 & 1.01 & 0.97 & 3.2 \\
\hline & Cylinder & $x y z$ & 1.00 & 0.91 & 8.7 & 1.00 & 0.89 & 8.8 & 1.00 & 0.97 & 3.9 & 1.02 & 0.97 & 3.8 \\
\hline \multirow{6}{*}{$\begin{array}{l}\text { Legume } \\
\text { in } \\
\text { mixture }\end{array}$} & Hull,p & uniform & 0.97 & 0.69 & 10.4 & 1.02 & 0.93 & 10.7 & 1.04 & 0.92 & 4.4 & 1.03 & 0.81 & 7.3 \\
\hline & Hull,s & uniform & 0.93 & 0.81 & 10.2 & 1.00 & 0.96 & 7.0 & 0.91 & 0.98 & 9.5 & 0.97 & 0.99 & 3.3 \\
\hline & Hull,p & z & 1.00 & 0.77 & 7.9 & 1.04 & 0.85 & 17.6 & 1.03 & 0.97 & 2.6 & 1.02 & 0.98 & 2.9 \\
\hline & Cylinder & z & 1.02 & 0.58 & 12.0 & 0.99 & 0.93 & 8.0 & 1.08 & 0.97 & 7.2 & 1.05 & 0.98 & 5.3 \\
\hline & Hull,p & $x y z$ & 0.97 & 0.75 & 9.6 & 1.02 & 0.84 & 16.8 & 0.96 & 0.88 & 4.9 & 0.94 & 0.90 & 7.1 \\
\hline & Cylinder & $x y z$ & 1.00 & 0.73 & 9.2 & 0.98 & 0.86 & 10.6 & 1.01 & 0.90 & 3.7 & 0.97 & 0.81 & 5.5 \\
\hline \multirow{6}{*}{$\begin{array}{l}\text { Grass } \\
\text { in } \\
\text { mixture }\end{array}$} & Hull,p & uniform & 1.37 & 0.70 & 27.0 & 1.18 & 0.38 & 23.2 & 1.10 & 0.86 & 11.4 & 1.38 & 0.78 & 27.1 \\
\hline & Hull,s & uniform & 0.97 & 0.90 & 8.7 & 1.00 & 0.91 & 10.5 & 0.98 & 0.96 & 5.1 & 0.97 & 0.97 & 5.3 \\
\hline & Hull,p & z & 0.94 & 0.52 & 15.8 & 1.05 & 0.65 & 18.4 & 1.04 & 0.97 & 3.6 & 1.07 & 0.92 & 6.5 \\
\hline & Cylinder & z & 1.18 & 0.84 & 15.2 & 1.02 & 0.35 & 26.4 & 1.04 & 0.98 & 4.2 & 1.09 & 0.91 & 8.9 \\
\hline & Hull,p & $x y z$ & 0.98 & 0.76 & 10.9 & 1.06 & 0.69 & 20.4 & 1.01 & 0.98 & 3.0 & 1.02 & 0.84 & 5.1 \\
\hline & Cylinder & $x y z$ & 1.14 & 0.81 & 13.8 & 1.05 & 0.68 & 16.5 & 1.02 & 0.99 & 2.8 & 1.03 & 0.89 & 4.7 \\
\hline
\end{tabular}


Table 6

\begin{tabular}{|c|c|c|c|c|c|c|c|c|c|c|c|c|c|c|}
\hline & \multirow{3}{*}{ Envelop } & \multirow{3}{*}{$\begin{array}{l}\text { angle } \\
\text { dist. }\end{array}$} & \multicolumn{6}{|c|}{$\mathrm{HD}$} & \multicolumn{6}{|c|}{ LD } \\
\hline & & & \multicolumn{3}{|c|}{ stage 1} & \multicolumn{3}{|c|}{ stage 2} & \multicolumn{3}{|c|}{ stage 1} & \multicolumn{3}{|c|}{ stage 2} \\
\hline & & & $a$ & $r^{2}$ & $\mathrm{CV}_{\text {rmse }}(\%)$ & $\mathrm{a}$ & $r^{2}$ & $\mathrm{CV}_{\text {rmse }}(\%)$ & $\mathrm{a}$ & $r^{2}$ & $\mathrm{CV}_{\text {rmse }}(\%)$ & $a$ & $r^{2}$ & $\mathrm{CV}_{\text {rmse }}(\%)$ \\
\hline \multirow{4}{*}{$\begin{array}{l}\text { Pure } \\
\text { legume }\end{array}$} & Hull,p & plagio & 0.98 & 0.83 & 16.8 & 1.04 & 0.95 & 19.3 & 0.96 & 0.97 & 5.4 & 0.99 & 0.95 & 11.2 \\
\hline & Cylinder & plagio & 0.97 & 0.83 & 15.8 & 1.00 & 0.98 & 10.9 & 1.00 & 0.98 & 4.7 & 0.98 & 0.85 & 17.4 \\
\hline & Hull,p & erect & 0.95 & 0.80 & 18.6 & 1.03 & 0.93 & 22.4 & 0.89 & 0.98 & 11.2 & 0.98 & 0.95 & 11.0 \\
\hline & Cylinder & erect & 0.95 & 0.76 & 19.3 & 0.99 & 0.98 & 12.0 & 0.91 & 0.97 & 9.1 & 0.97 & 0.83 & 19.0 \\
\hline \multirow{4}{*}{$\begin{array}{l}\text { Pure } \\
\text { grass }\end{array}$} & Hull,p & erect & 1.00 & 0.85 & 11.6 & 1.02 & 0.90 & 10.2 & 1.01 & 0.98 & 3.5 & 1.01 & 0.97 & 3.8 \\
\hline & Cylinder & erect & 1.00 & 0.91 & 8.8 & 1.00 & 0.90 & 8.8 & 1.01 & 0.98 & 3.9 & 1.02 & 0.97 & 4.1 \\
\hline & Hull,p & plagio & 1.03 & 0.81 & 14.1 & 1.06 & 0.87 & 12.9 & 1.13 & 0.98 & 11.7 & 1.19 & 0.97 & 16.0 \\
\hline & Cylinder & plagio & 1.02 & 0.86 & 11.9 & 1.05 & 0.89 & 10.1 & 1.14 & 0.98 & 12.2 & 1.21 & 0.97 & 17.2 \\
\hline \multirow{4}{*}{$\begin{array}{c}\text { Legume } \\
\text { in } \\
\text { mixture }\end{array}$} & Hull,p & plagio & 0.97 & 0.77 & 9.9 & 1.01 & 0.87 & 14.8 & 0.96 & 0.84 & 5.5 & 0.94 & 0.88 & 7.5 \\
\hline & Cylinder & plagio & 1.00 & 0.75 & 10.0 & 0.97 & 0.84 & 11.2 & 1.01 & 0.86 & 4.4 & 0.97 & 0.76 & 7.4 \\
\hline & Hull,p & erect & 0.93 & 0.73 & 13.4 & 0.99 & 0.85 & 15.4 & 0.90 & 0.89 & 11.2 & 0.92 & 0.85 & 9.6 \\
\hline & Cylinder & erect & 0.94 & 0.72 & 11.5 & 0.96 & 0.86 & 8.6 & 0.94 & 0.85 & 6.9 & 0.94 & 0.84 & 7.5 \\
\hline \multirow{4}{*}{$\begin{array}{l}\text { Grass } \\
\text { in } \\
\text { mixture }\end{array}$} & Hull,p & erect & 0.98 & 0.75 & 11.0 & 1.07 & 0.67 & 22.8 & 1.01 & 0.98 & 3.9 & 1.02 & 0.87 & 4.7 \\
\hline & Cylinder & erect & 1.14 & 0.81 & 14.6 & 1.07 & 0.68 & 18.3 & 1.02 & 0.98 & 3.2 & 1.04 & 0.84 & 6.1 \\
\hline & Hull,p & plagio & 1.17 & 0.64 & 17.6 & 1.38 & 0.61 & 31.4 & 0.96 & 0.44 & 26.7 & 1.56 & 0.12 & 43.1 \\
\hline & Cylinder & plagio & 1.42 & 0.77 & 28.6 & 1.39 & 0.59 & 31.8 & 0.99 & 0.45 & 27.3 & 1.63 & 0.13 & 44.0 \\
\hline
\end{tabular}

5 
Supplementary material - Table A

\begin{tabular}{|c|c|c|c|c|c|c|c|c|c|c|c|c|c|c|}
\hline & \multirow{3}{*}{ Envelope } & \multirow{3}{*}{$\begin{array}{l}\text { Leaf } \\
\text { dist. }\end{array}$} & \multicolumn{6}{|c|}{$\mathrm{HD}$} & \multicolumn{6}{|c|}{ LD } \\
\hline & & & \multicolumn{3}{|c|}{ stage 1} & \multicolumn{3}{|c|}{ stage 2} & \multicolumn{3}{|c|}{ stage 1} & \multicolumn{3}{|c|}{ stage 2} \\
\hline & & & $\mathrm{a}$ & $r^{2}$ & $\mathrm{CV}_{\text {rmse }}(\%)$ & $\mathrm{a}$ & $r^{2}$ & $\mathrm{CV}_{\text {rmse }}(\%)$ & $\mathrm{a}$ & $r^{2}$ & $\mathrm{CV}_{\text {rmse }}(\%)$ & $\mathrm{a}$ & $r^{2}$ & $\mathrm{CV}_{\text {rmse }}(\%)$ \\
\hline \multirow{8}{*}{$\begin{array}{c}\text { Pure } \\
\text { legume }\end{array}$} & Hull,p & $z$ & 0.97 & 0.83 & 14.3 & 1.06 & 0.95 & 18.9 & 1.02 & 0.99 & 4.0 & 1.04 & 0.97 & 9.6 \\
\hline & Ellipsoid & $z$ & 0.97 & 0.80 & 17.1 & 1.05 & 0.97 & 13.9 & 1.05 & 0.99 & 4.9 & 1.02 & 0.93 & 12.7 \\
\hline & Cylinder & $z$ & 0.98 & 0.85 & 14.9 & 1.03 & 0.97 & 13.8 & 1.05 & 0.98 & 5.5 & 1.02 & 0.90 & 16.4 \\
\hline & Tessel & $z$ & 0.95 & 0.73 & 17.3 & 0.84 & 0.86 & 23.8 & 1.06 & 0.98 & 5.9 & 0.94 & 0.80 & 19.3 \\
\hline & Hull,p & $x y z$ & 0.98 & 0.82 & 17.6 & 1.04 & 0.95 & 18.4 & 0.96 & 0.97 & 6.0 & 1.00 & 0.96 & 9.7 \\
\hline & Ellipsoid & $x y z$ & 0.97 & 0.81 & 17.0 & 1.01 & 0.99 & 9.1 & 0.98 & 0.97 & 4.9 & 0.99 & 0.91 & 15.5 \\
\hline & Cylinder & $x y z$ & 0.97 & 0.84 & 15.1 & 0.99 & 0.98 & 10.3 & 0.99 & 0.97 & 5.0 & 1.00 & 0.89 & 16.1 \\
\hline & Tessel & $x y z$ & 0.93 & 0.58 & 19.7 & 0.79 & 0.76 & 29.1 & 0.99 & 0.98 & 5.0 & 0.88 & 0.69 & 23.7 \\
\hline \multirow{8}{*}{$\begin{array}{l}\text { Pure } \\
\text { grass }\end{array}$} & Hull,p & $z$ & 1.00 & 0.89 & 10.3 & 1.02 & 0.84 & 13.3 & 1.02 & 0.97 & 4.7 & 1.05 & 0.95 & 6.2 \\
\hline & Ellipsoid & $z$ & 1.08 & 0.57 & 21.2 & 1.02 & 0.87 & 10.7 & 1.04 & 0.92 & 8.5 & 1.05 & 0.94 & 6.9 \\
\hline & Cylinder & $z$ & 1.00 & 0.90 & 10.2 & 1.01 & 0.92 & 7.4 & 1.02 & 0.97 & 4.7 & 1.05 & 0.95 & 6.4 \\
\hline & Tessel & $z$ & 0.98 & 0.66 & 14.1 & 0.97 & 0.78 & 10.6 & 0.98 & 0.95 & 5.5 & 1.02 & 0.97 & 3.9 \\
\hline & Hull,p & $x y z$ & 1.00 & 0.87 & 11.4 & 1.01 & 0.91 & 9.2 & 1.01 & 0.98 & 3.6 & 1.01 & 0.97 & 3.2 \\
\hline & Ellipsoid & $x y z$ & 1.00 & 0.79 & 12.6 & 1.01 & 0.87 & 10.4 & 1.01 & 0.97 & 5.0 & 1.01 & 0.96 & 3.8 \\
\hline & Cylinder & $x y z$ & 1.00 & 0.91 & 8.7 & 1.00 & 0.89 & 8.8 & 1.00 & 0.97 & 3.9 & 1.02 & 0.97 & 3.8 \\
\hline & Tessel & $x y z$ & 0.96 & 0.59 & 15.0 & 0.95 & 0.75 & 11.9 & 0.91 & 0.95 & 9.9 & 0.92 & 0.94 & 8.3 \\
\hline \multirow{8}{*}{ 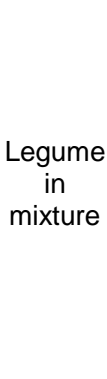 } & Hull,p & $z$ & 1.00 & 0.77 & 7.9 & 1.04 & 0.85 & 17.6 & 1.03 & 0.97 & 2.6 & 1.02 & 0.98 & 2.9 \\
\hline & Ellipsoid & $z$ & 0.99 & 0.52 & 11.9 & 0.99 & 0.88 & 10.5 & 1.05 & 0.93 & 5.1 & 1.04 & 0.96 & 4.4 \\
\hline & Cylinder & $z$ & 1.02 & 0.58 & 12.0 & 0.99 & 0.93 & 8.0 & 1.08 & 0.97 & 7.2 & 1.05 & 0.98 & 5.3 \\
\hline & Tessel & $z$ & $0.44^{i}$ & 0.45 & 14.1 & $0.54^{i}$ & 0.65 & 19.3 & 1.05 & 0.91 & 5.7 & 0.96 & 0.79 & 6.8 \\
\hline & Hull,p & $x y z$ & 0.97 & 0.75 & 9.6 & 1.02 & 0.84 & 16.8 & 0.96 & 0.88 & 4.9 & 0.94 & 0.90 & 7.1 \\
\hline & Ellipsoid & $x y z$ & 0.97 & 0.70 & 10.9 & 0.98 & 0.85 & 11.2 & 0.99 & 0.86 & 4.4 & 0.96 & 0.83 & 5.3 \\
\hline & Cylinder & $x y z$ & 1.00 & 0.73 & 9.2 & 0.98 & 0.86 & 10.6 & 1.01 & 0.90 & 3.7 & 0.97 & 0.81 & 5.5 \\
\hline & Tessel & $x y z$ & $0.39^{i}$ & 0.45 & 17.3 & $0.46^{i}$ & 0.58 & 21.3 & 0.98 & 0.89 & 3.3 & 0.88 & 0.57 & 13.9 \\
\hline \multirow{8}{*}{$\begin{array}{l}\text { Grass } \\
\text { in } \\
\text { mixture }\end{array}$} & Hull,p & $z$ & 0.94 & 0.52 & 15.8 & 1.05 & 0.65 & 18.4 & 1.04 & 0.97 & 3.6 & 1.07 & 0.92 & 6.5 \\
\hline & Ellipsoid & $z$ & 1.12 & 0.72 & 16.7 & 1.03 & 0.46 & 21.8 & 1.08 & 0.91 & 8.3 & 1.14 & 0.88 & 12.2 \\
\hline & Cylinder & $z$ & 1.18 & 0.84 & 15.2 & 1.02 & 0.35 & 26.4 & 1.04 & 0.98 & 4.2 & 1.09 & 0.91 & 8.9 \\
\hline & Tessel & $z$ & 1.09 & 0.76 & 15.3 & 0.95 & 0.72 & 17.9 & 0.96 & 0.98 & 4.8 & 1.01 & 0.97 & 3.0 \\
\hline & Hull,p & $x y z$ & 0.98 & 0.76 & 10.9 & 1.06 & 0.69 & 20.4 & 1.01 & 0.98 & 3.0 & 1.02 & 0.85 & 5.1 \\
\hline & Ellipsoid & $x y z$ & 1.16 & 0.71 & 17.5 & 1.05 & 0.57 & 19.9 & 1.03 & 0.96 & 5.6 & 1.03 & 0.85 & 5.7 \\
\hline & Cylinder & $x y z$ & 1.14 & 0.81 & 13.8 & 1.05 & 0.68 & 16.5 & 1.02 & 0.99 & 2.8 & 1.03 & 0.90 & 4.7 \\
\hline & Tessel & $x y z$ & 1.01 & 0.73 & 16.8 & 0.83 & 0.55 & 24.3 & 0.86 & 0.93 & 15.9 & 0.88 & 0.82 & 13.8 \\
\hline
\end{tabular}


a) HD (stage 1)
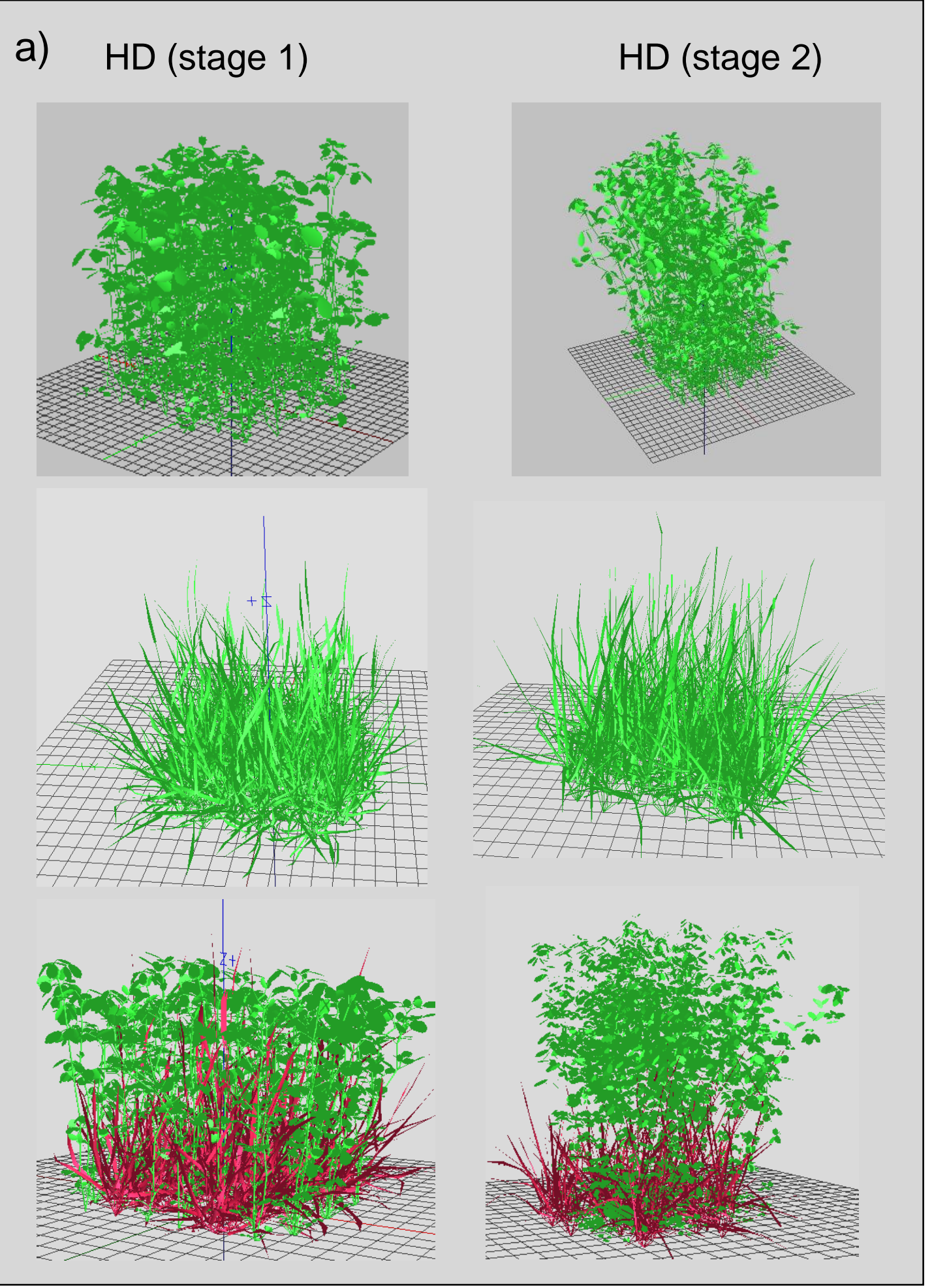

HD (stage 2)
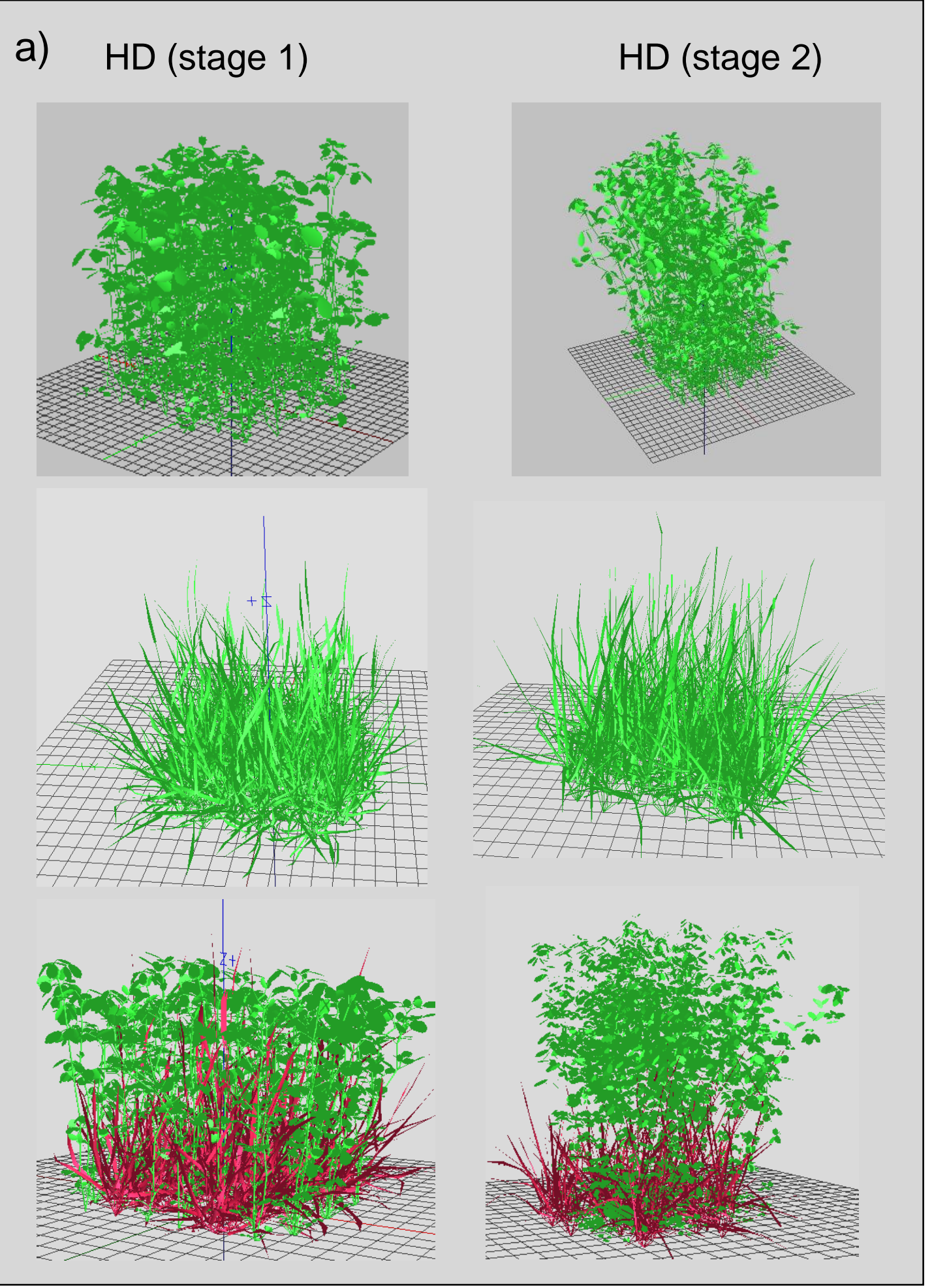

(

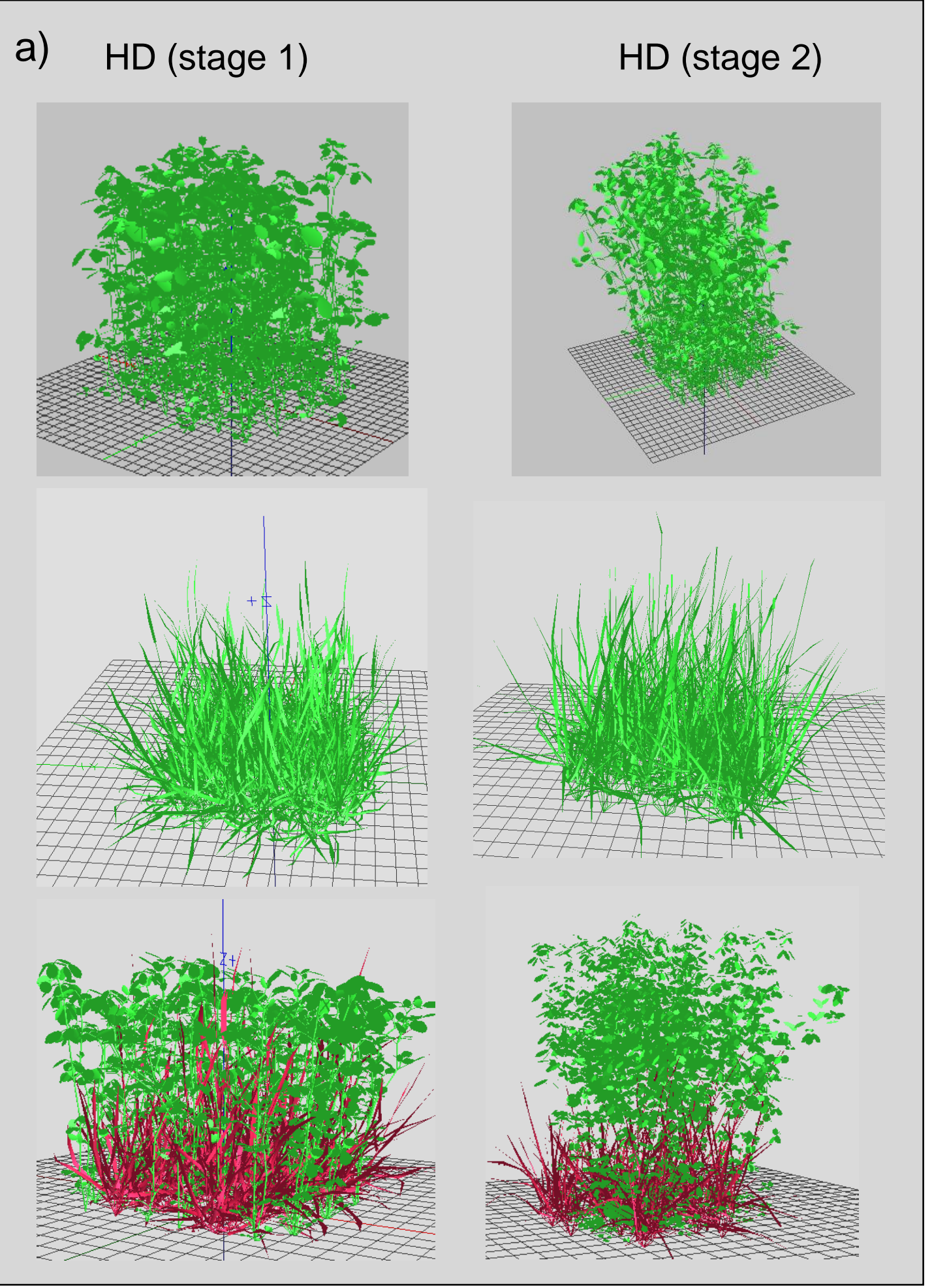

b) LD (stage 1)

LD (stage 2)
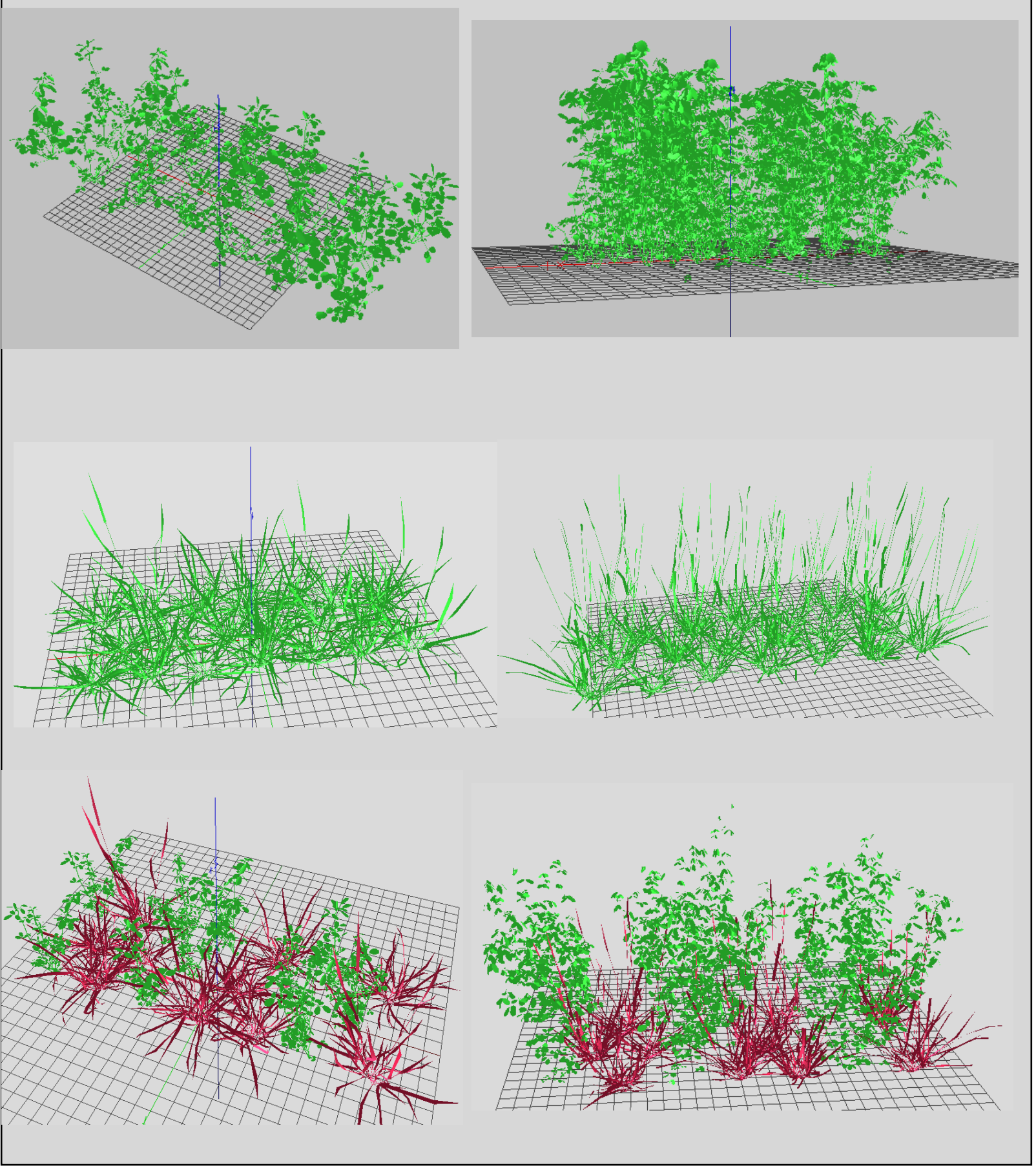


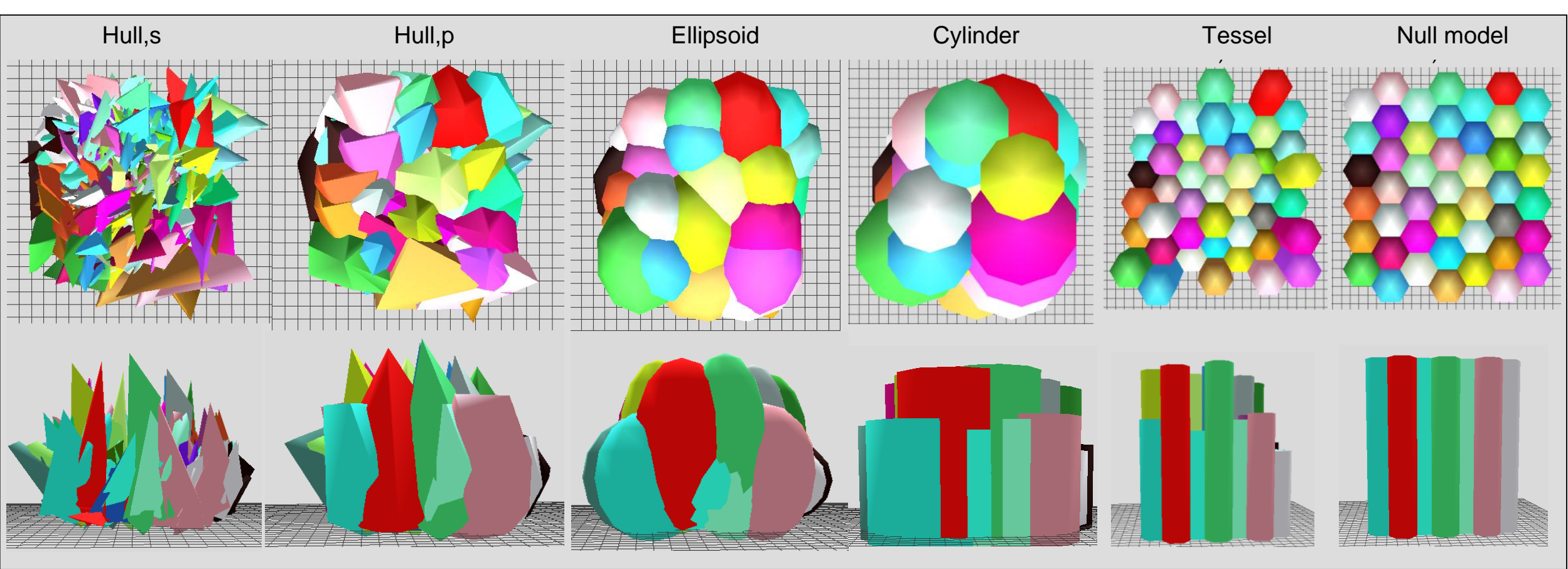



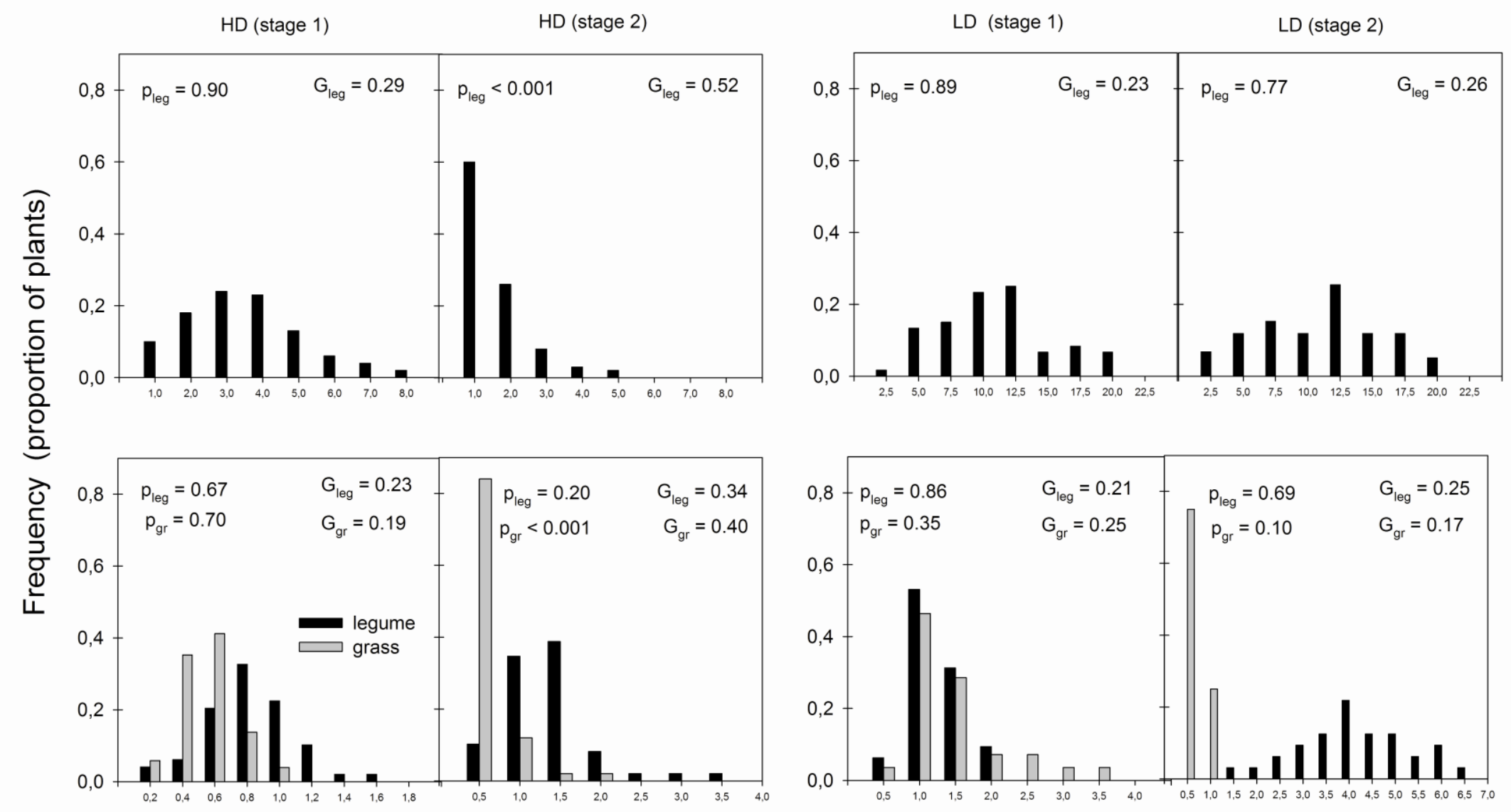

Plant mass (g) 
Figure 4
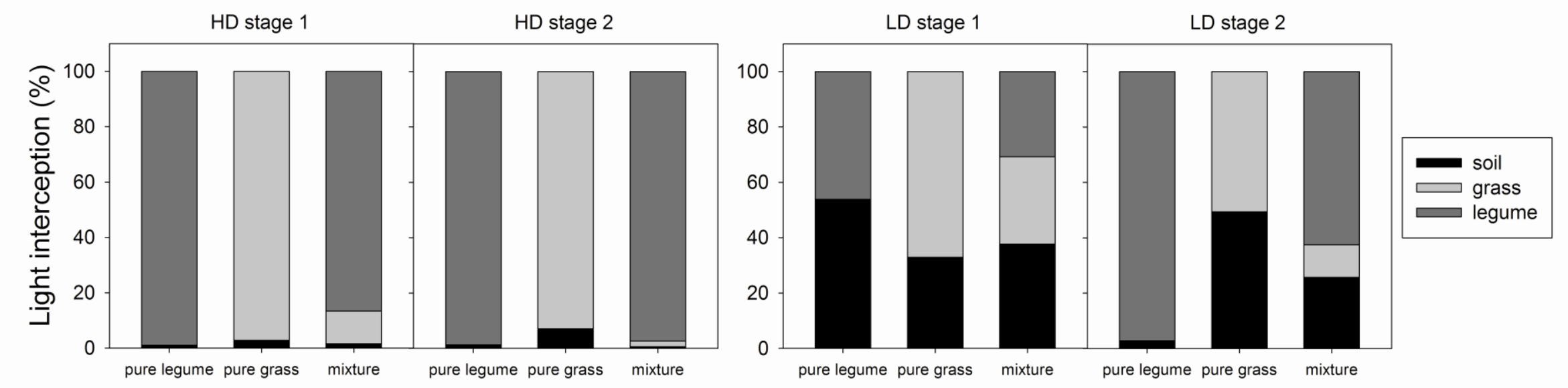


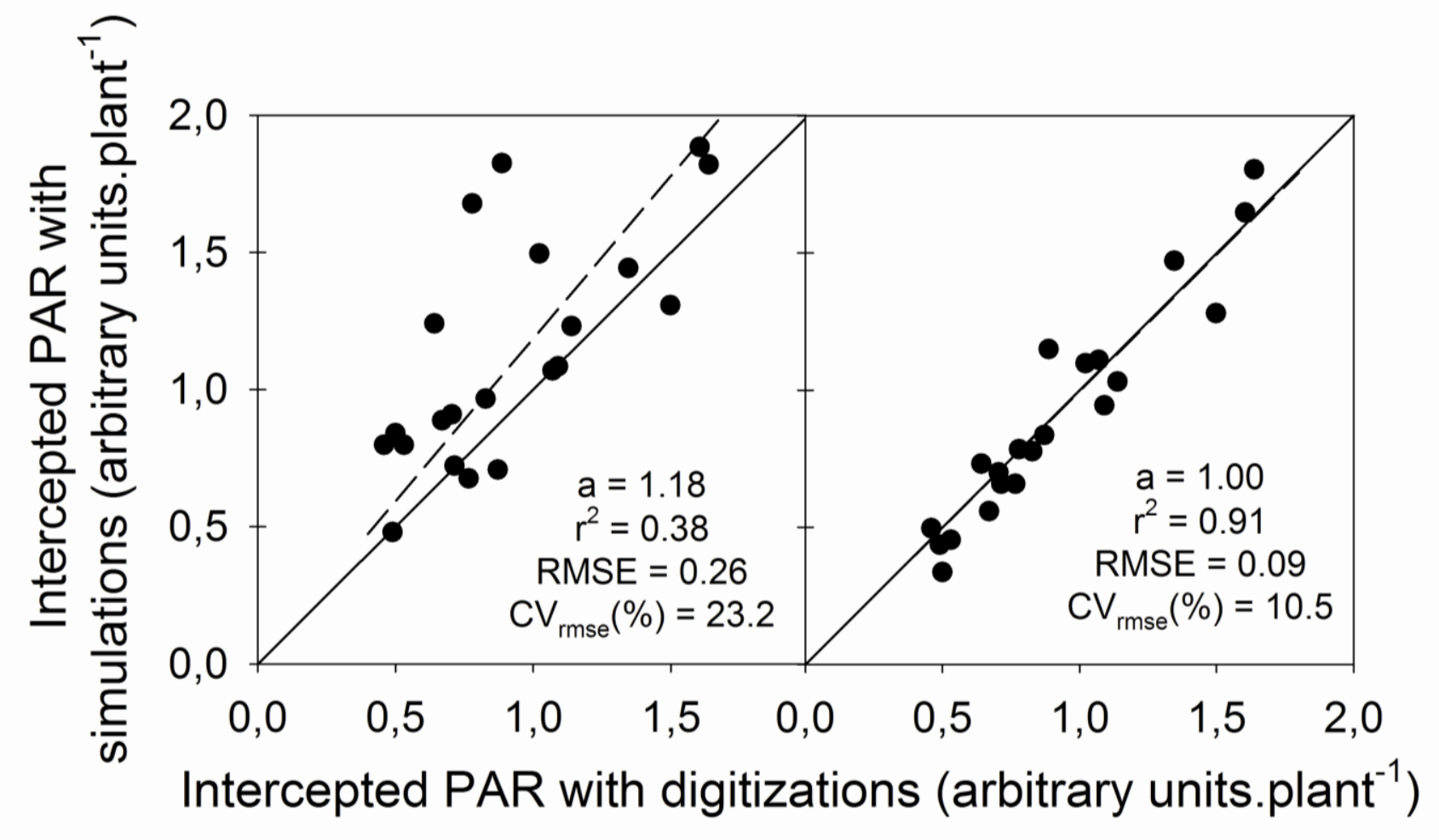



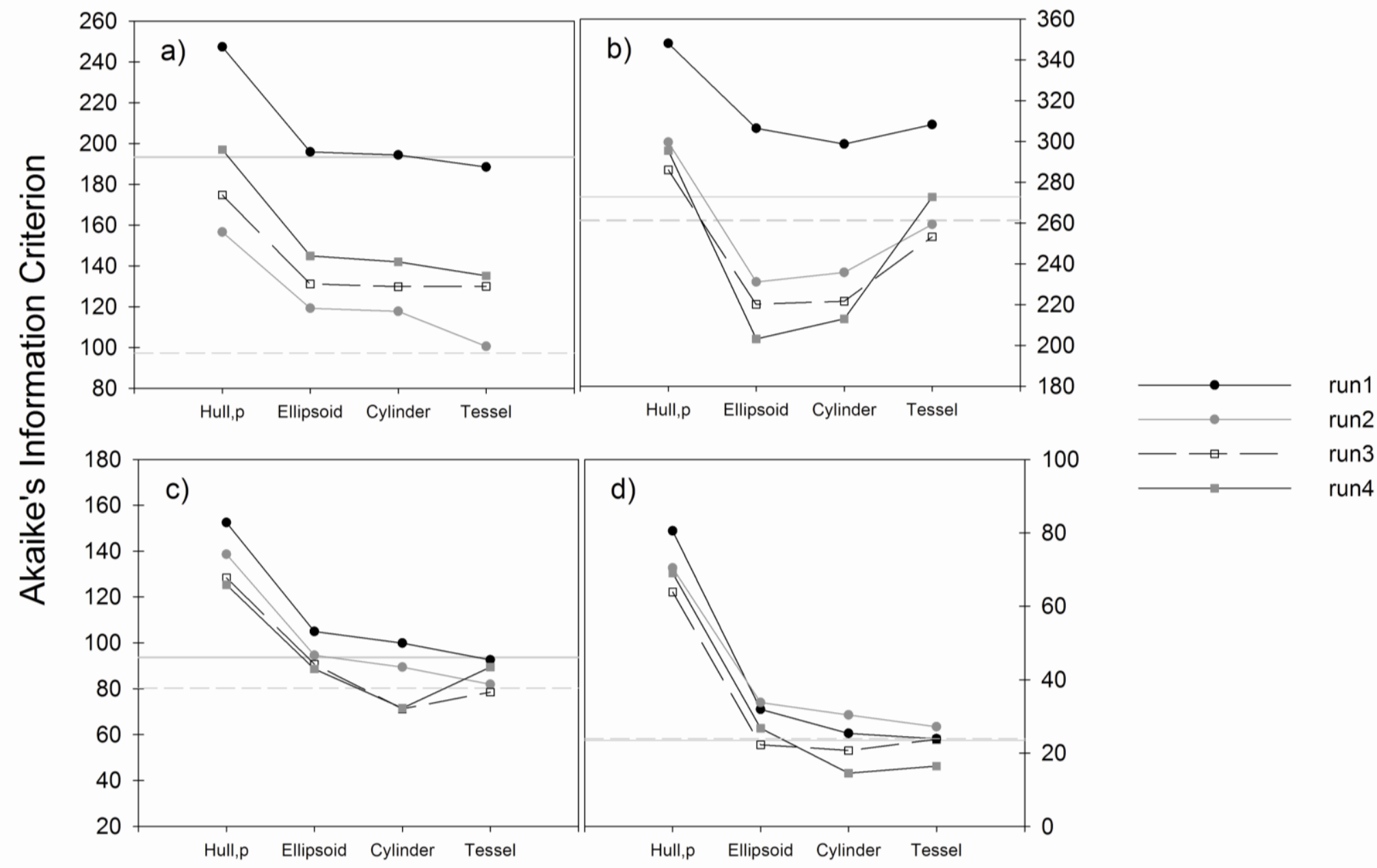

\section{Envelope-based reconstruction model}




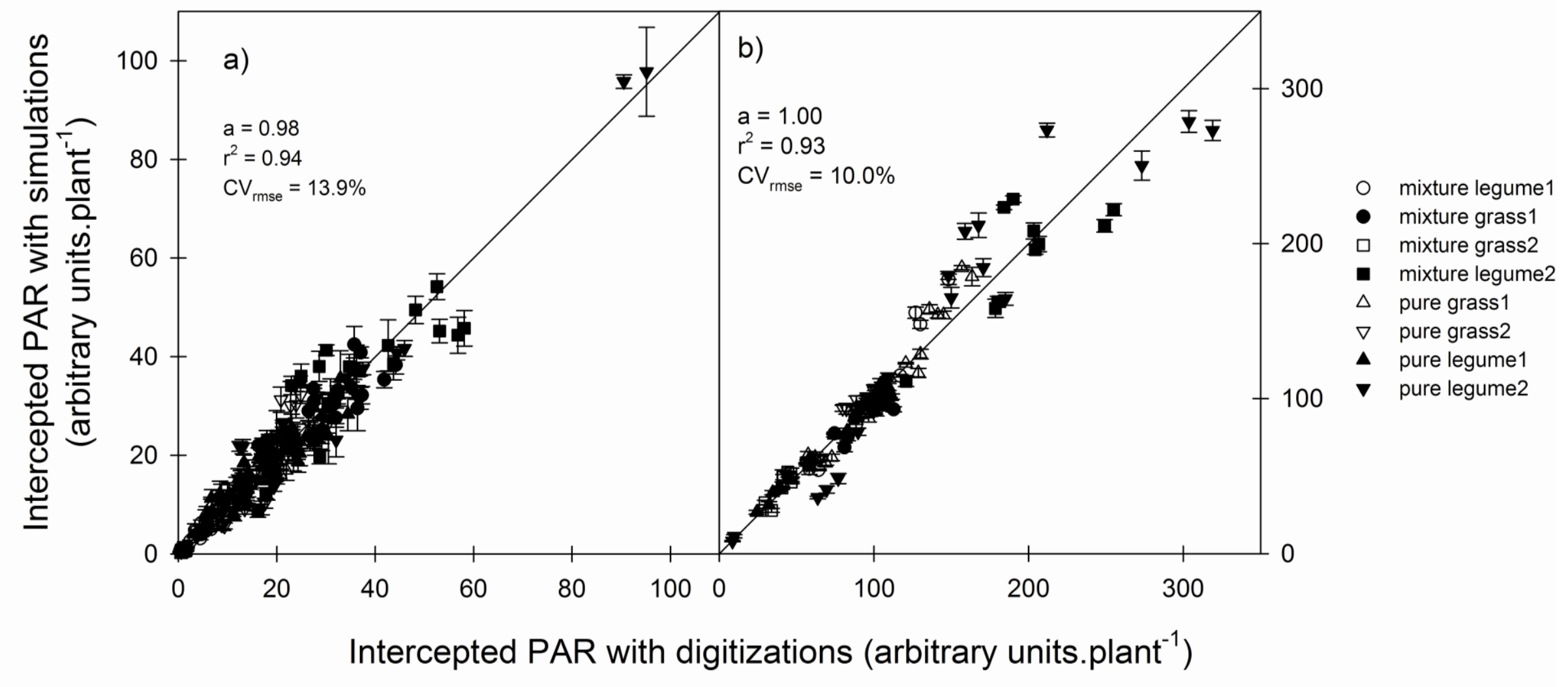




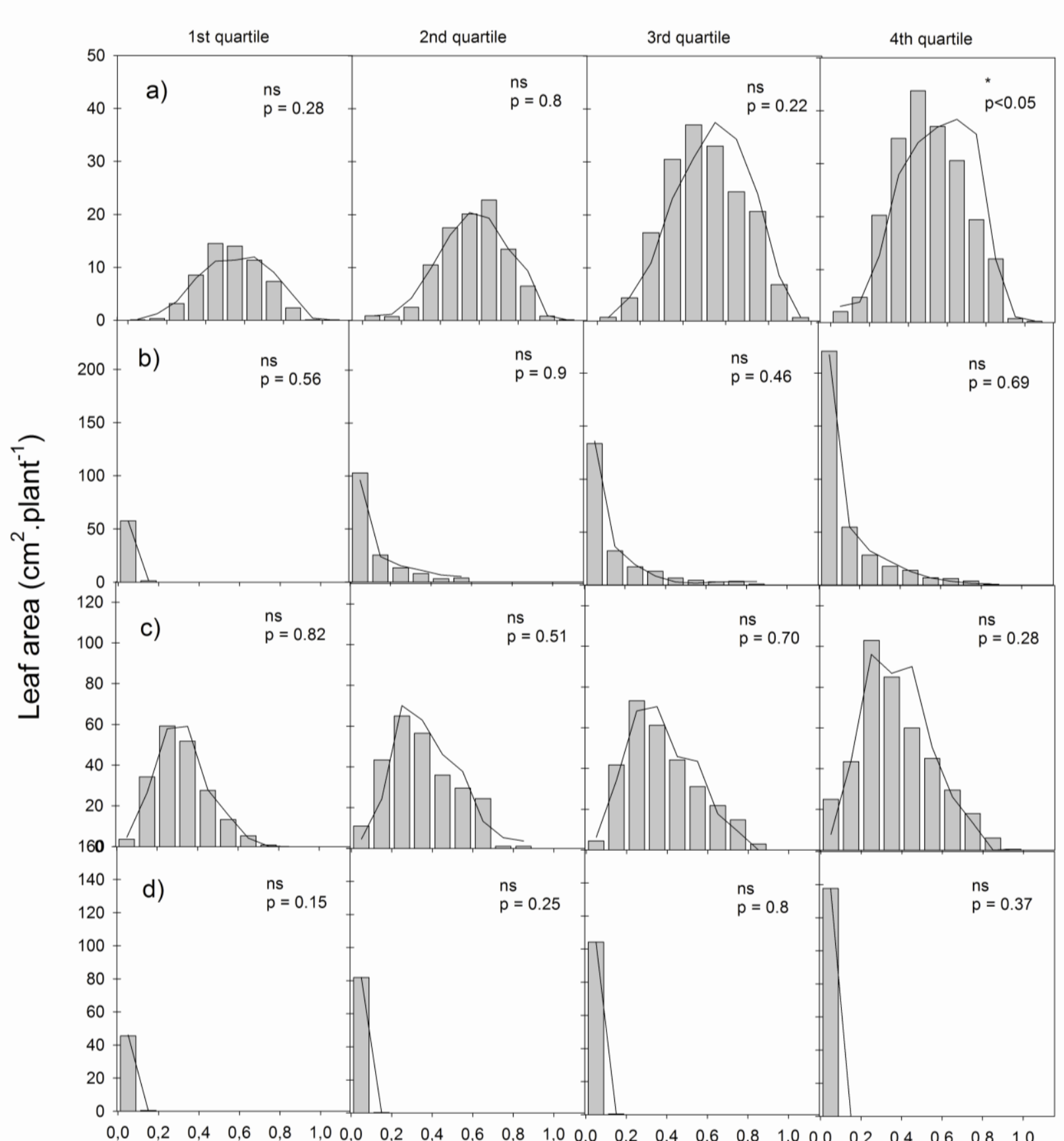

Classes of light intensity (proportion of incoming PAR) 


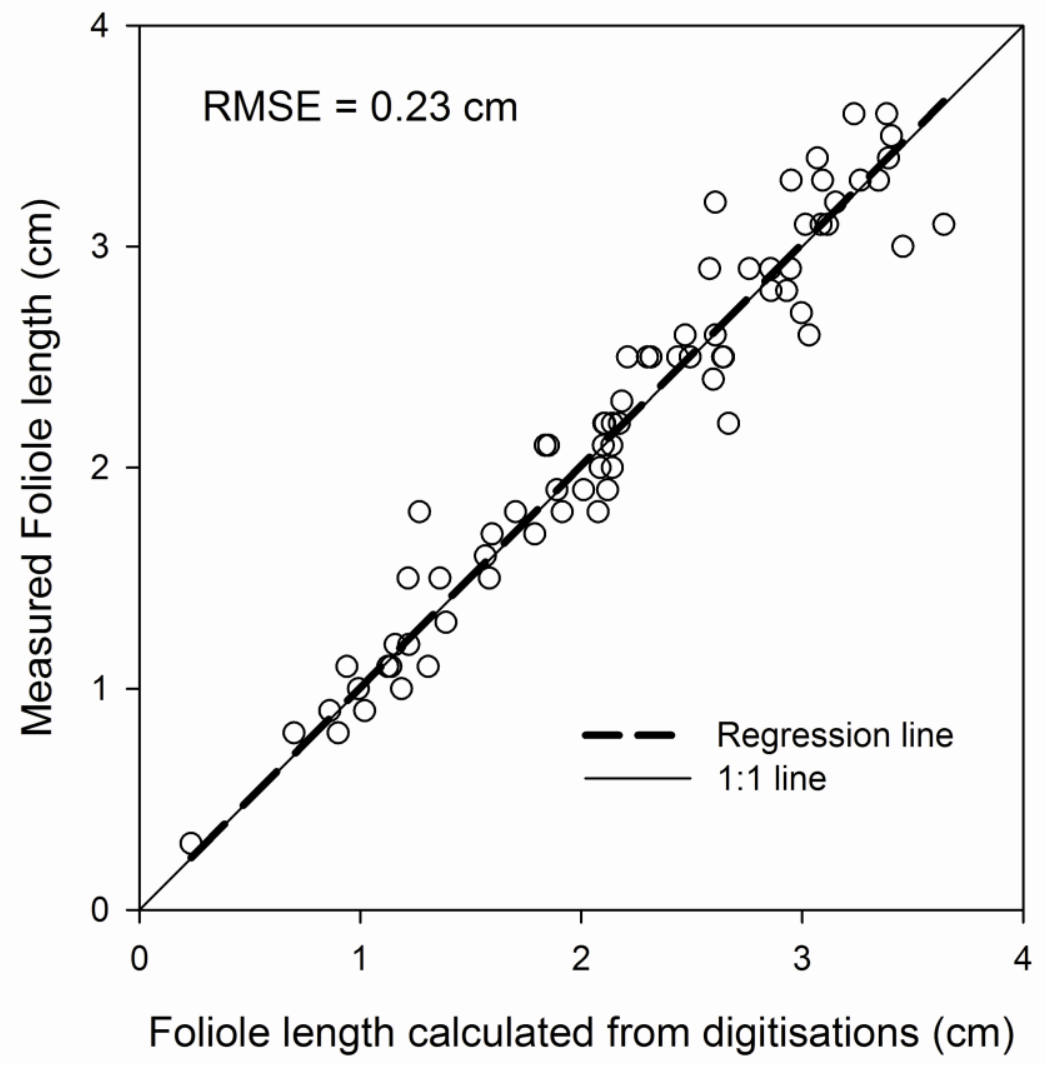

